Article

\title{
Differential Influence of Pueraria lobata Root Extract and Its Main Isoflavones on Ghrelin Levels in Alcohol-Treated Rats
}

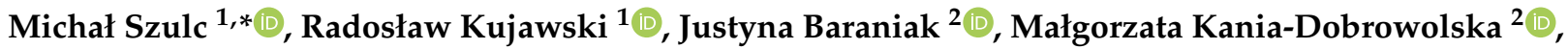 \\ Ewa Kamińska ${ }^{1}$, Agnieszka Gryszczyńska ${ }^{2}$ (D), Kamila Czora-Poczwardowska ${ }^{1}$, Hanna Winiarska ${ }^{1}$ (D) \\ and Przemysław Ł. Mikołajczak 1,2 (D)
}

1 Department of Pharmacology, Poznań University of Medical Sciences, Rokietnicka 5a, 60-806 Poznan, Poland; radkuj@ump.edu.pl (R.K.); awekam@ump.edu.pl (E.K.); kczora@ump.edu.pl (K.C.-P.);

hwiniar@ump.edu.pl (H.W.); przemmik@ump.edu.pl (P.Ł.M.)

2 Department of Pharmacology and Phytochemistry, Institute of Natural Fibres and Medicinal Plants, Kolejowa 2, 62-064 Plewiska, Poland; justyna.baraniak@iwnirz.pl (J.B.);

malgorzata.kania@iwnirz.pl (M.K.-D.); agnieszka.gryszczynska@iwnirz.pl (A.G.)

* Correspondence: mszulc@ump.edu.pl

Citation: Szulc, M.; Kujawski, R.; Baraniak, J.; Kania-Dobrowolska, M.; Kamińska, E.; Gryszczyńska, A.;

Czora-Poczwardowska, K.; Winiarska, H.; Mikołajczak, P.Ł. Differential Influence of Pueraria lobata Root Extract and Its Main Isoflavones on Ghrelin Levels in Alcohol-Treated Rats. Pharmaceuticals 2022, 15, 25. https://doi.org/ $10.3390 /$ ph15010025

Academic Editor: Paweł Kafarski

Received: 22 November 2021

Accepted: 22 December 2021

Published: 24 December 2021

Publisher's Note: MDPI stays neutral with regard to jurisdictional claims in published maps and institutional affiliations.

Copyright: (c) 2021 by the authors. Licensee MDPI, Basel, Switzerland. This article is an open access article distributed under the terms and conditions of the Creative Commons Attribution (CC BY) license (https:// creativecommons.org/licenses/by/ $4.0 /)$.

\begin{abstract}
The study was carried out on alcohol-preferring male Wistar rats. The following drugs were repeatedly $(28 \times)$ administered: acamprosate $(500 \mathrm{mg} / \mathrm{kg}$, p.o.), naltrexone $(0.1 \mathrm{mg} / \mathrm{kg}$, i.p), and Pueraria lobata (kudzu) root extract (KU) $(500 \mathrm{mg} / \mathrm{kg}$, p.o.) and its isoflavones: daidzin (40 mg/kg, p.o.) and puerarin (150 mg/ $\mathrm{kg}$, p.o.). Their effects on a voluntary alcohol intake were assessed. KU and alcohol were also given for 9 days in an experiment on alcohol tolerance development. Finally, total and active ghrelin levels in peripheral blood serum were measured by ELISA method. Acamprosate, naltrexone, daidzin, and puerarin, reducing the alcohol intake, caused an increase in both forms of ghrelin levels. On the contrary, though KU inhibited the alcohol intake and alcohol tolerance development, it reduced ghrelin levels in alcohol-preferring rats. The changes of ghrelin concentration could play a role as an indicator of the currently used drugs. The other effect on the KU-induced shift in ghrelin levels in the presence of alcohol requires further detailed study.
\end{abstract}

Keywords: acamprosate; daidzin; naltrexone; puerarin; Pueraria lobata; alcohol intake; alcohol preferring rats; alcohol tolerance; ghrelin blood level

\section{Introduction}

Excessive alcohol consumption is a community-wide problem and can lead to many diseases [1]. Alcohol abuse has been on an upward trend over the past two years, most likely fueled by the COVID-19 epidemic [2]. The effects of excessive alcohol consumption include increased healthcare costs, alcohol-related crimes (e.g., assault and robbery), and motor vehicle accidents [3]. Long-term treatment of alcoholism is primarily based on detoxification; the patient undergoing psychotherapy is additionally supported by drugs that facilitate the rejection of alcohol [4-6]. Due to the lack of sufficiently effective drugs in this field, searching for new agents, including plant-derived substances that reduce the amount of alcohol consumed, is extremely promising $[7,8]$.

Pueraria lobata (Willd) Ohwi (kudzu, kudzu vine) is a plant [9] native to eastern Asia, possessing a long history of traditional usage as medicine in Asian countries, with roots as the main raw material for active substances, among others, flavonoids (isoflavones), isoflavone glucosides, organic acids, saponins, starch, and D-mannitol [9]. Three compounds from the group of isoflavones deserve particular attention, namely: daidzin (DAI), daidzein, and puerarin (PUE). P. lobata preparations and their main components have potential in an alcohol intake reduction [10], and thus in the long-term prevention of alcohol addiction, has been indicated in a number of studies over the past two decades [11-13]. For instance, DAI and daidzein effectively inhibited ethanol (EtOH) consumption in laboratory 
animals $[10,14]$. PUE has been also proved to dose-dependently reduce alcohol consumption [15] and to suppress alcohol withdrawal symptoms. The ability of PUE to decrease the amount of beer consumption and the increase in the time course of drinking was also proved in a clinical trial [16]. Several other clinical examinations provided further evidence of the ability to inhibit the amount or rate of alcohol consumption [17-20]. In addition to suppressing alcohol intake, plant remedies from kudzu also exhibit other interesting pharmacological activities, e.g., preventing obesity and improving glucose metabolism [21-23]. Other preclinical studies indicated their ability to ameliorate glucose and lipid metabolic disorders [24,25]. Anti-inflammatory and antioxidant activities of kudzu root extract (especially in the case of PUE) have also been demonstrated [26], and similar properties were observed in the leaves [27]. It is worth mentioning that PUE, the main constituent isolated from $P$. lobata roots, also revealed a beneficial effect on aging related diseases [9] and has received investigational drug status for the treatment of alcohol abuse as well as being listed in the DRUGBANK database [28].

A crucial part of the reward system in the brain is the cholinergic-dopaminergic pathway $[29,30]$, which is strongly associated with the reinforcing properties of rewards $[29,31]$. The influence of drug dependence on the reward system has been widely described for ghrelin and its receptor, GHS-R1A [30,32-35]. In general, ghrelin presence in the brain has been well documented $[30,36]$ and the active form of ghrelin passes the bloodbrain barrier [37], even when released or administered peripherally [38], and in this way, it may have central effects [30,39]. There are some studies on the role of GHS-R1A [40,41], which is down-regulated in the ventral tegmental area (VTA) in alcohol high-preferring rats, compared to low-alcohol consuming rats [40]. Several studies with the usage of GHS-R1A antagonists (i.e., JMV2959, BIM28163 or D-Lys3-GHRP-6) strongly supported the assumption stating that ghrelin signaling regulates alcohol intake in high-alcohol consuming Wistar rats, as well as in alcohol-preferring (AA) rats $[40,42,43]$. Moreover, the alcohol reward disruption and the alcohol-induced locomotor stimulation and dopamine release in nucleus accumbens (NAc) was observed in ghrelin knockout mice [44,45]. Interestingly, the nature of the interaction processes between ghrelin and GHS-R1a receptors, documented particularly in appetite signaling and closely related to reward behavior [34], has an ability to dimerize with several additional G protein-coupled receptors (GPCRs), including the GHS-R1b receptor [46]. Their molecular mechanism of action during EtOH addiction development remains unclear [36].

Interesting observations were made in the course of the analysis of changes in the peripheral concentration of ghrelin, both in rodents [47-49] and in clinical trials [50-53] under conditions of significant ethanol consumption. Results from clinical observations support data showing that active drinking in alcohol-dependent individuals may suppress both ghrelin levels and its production [50-52], observed in our previous study on highalcohol preferring rats as well [47]. Active form of ghrelin (acyl-ghrelin) elevation by EtOH during early adolescence was observed [48]. Experiments in model animals (two-bottle choice protocol) indicate that the key role of the ghrelin signaling pathway in lowering of alcohol voluntary intake appears to be equal for both sexes [49].

With the above in mind, the aim of this study was to determine the role of P. lobata root extract (KU) and its main isoflavones (PUE, DAI) on ghrelin blood level in the experimental model of alcohol dependence. It is the quest for a correlation between the ability of KU to reduce alcohol drinking behavior using free choice procedure and the concentration of both forms of ghrelin in rats. Furthermore, the effect of KU on alcohol tolerance development coupled with ghrelin blood level was an additional research target. The influences of KU, PUE, and DAI on ghrelin levels were compared to the effects of standard drugs used to inhibit the alcohol drinking reflex, i.e., acamprosate (AC) and naltrexone (NAL). The chemical structures of these compounds are presented in Figure 1. 


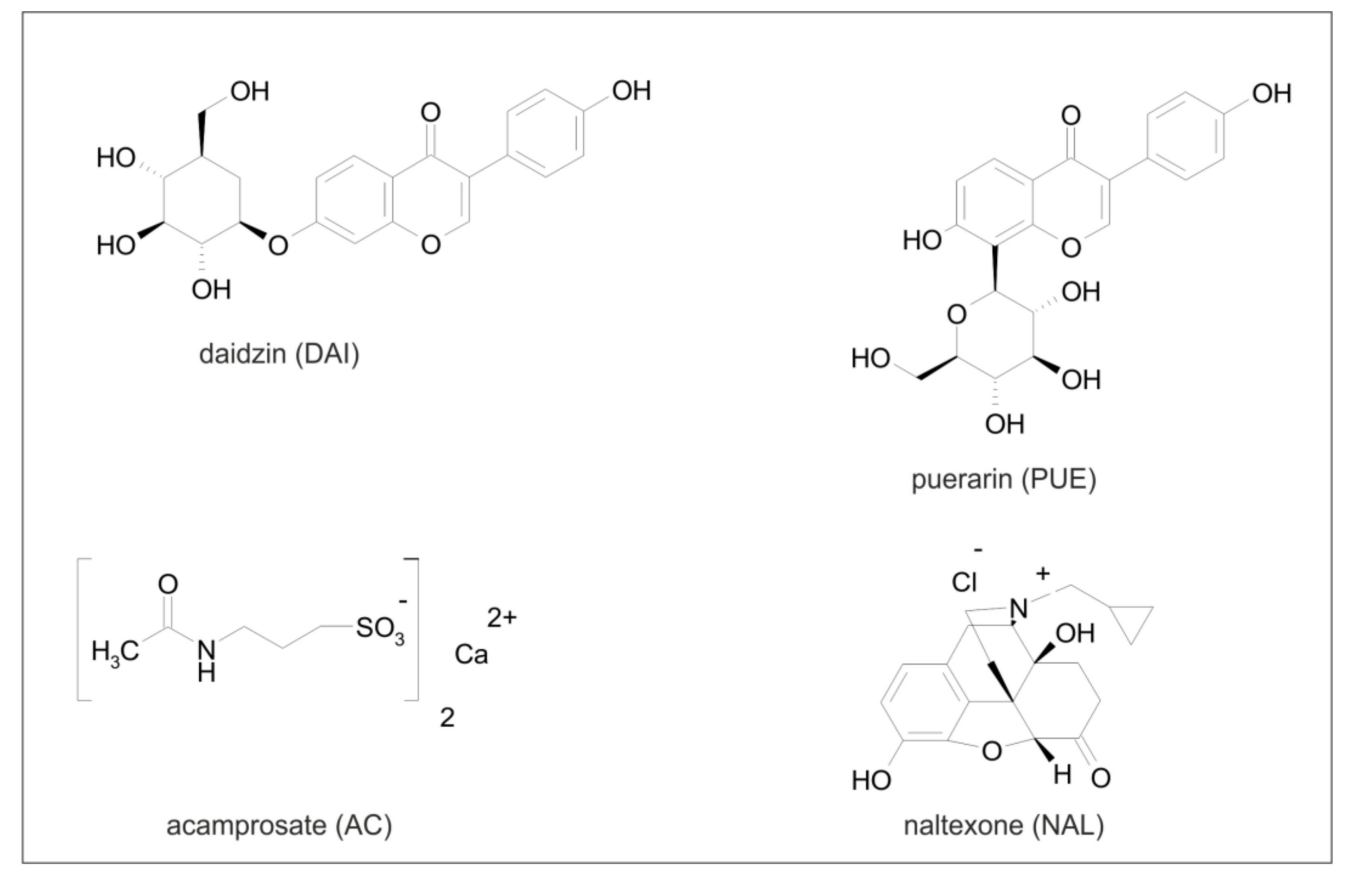

Figure 1. Chemical structures of the main kudzu flavonoids-DAI and PUE (used in this work), and classic drugs that inhibit the drinking reflex (AC, NAL).

\section{Results}

\subsection{Content of Isoflavones in KU}

The HPLC-DAD chromatogram of the isoflavones contained in KU is presented in Figure 2.

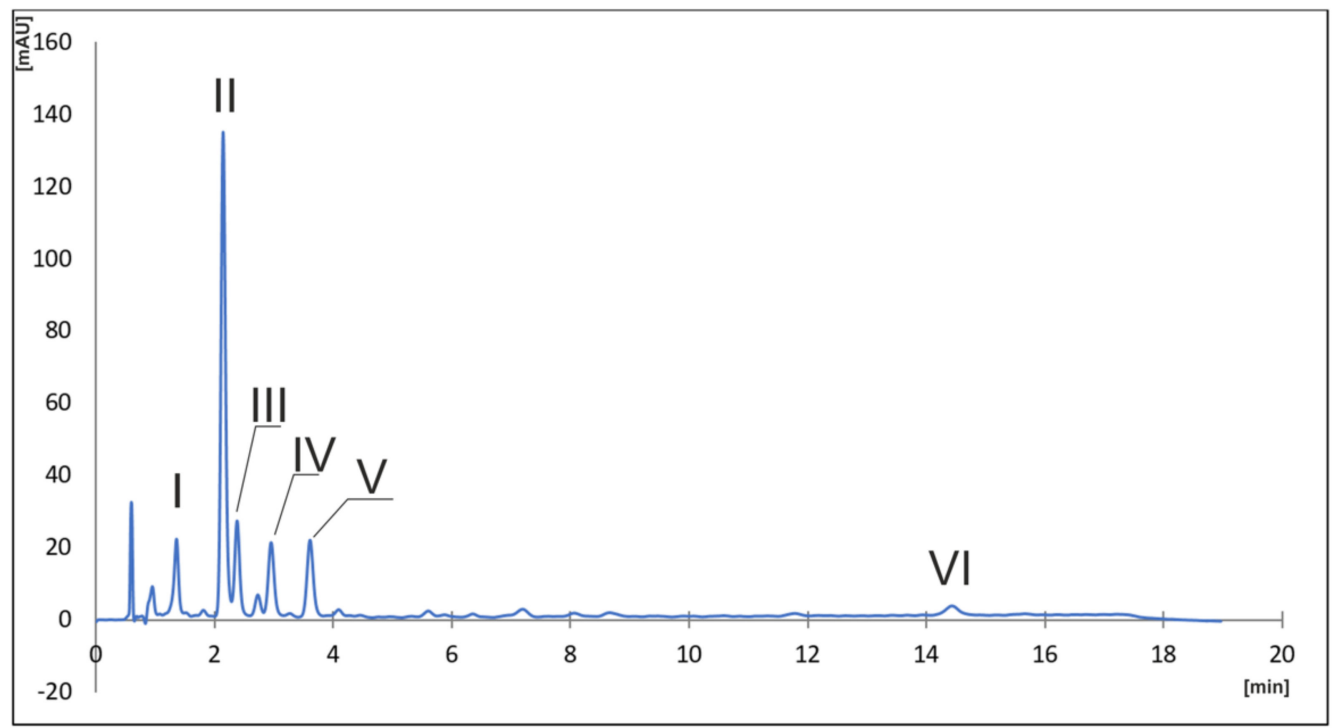

Figure 2. HPLC-DAD chromatogram of kudzu extract (KU) separation $(\lambda=260 \mathrm{~nm})$. (I) 3-hydroxypuerarin, $\mathrm{t}=1.3 \mathrm{~min}$; (II) puerarin, $\mathrm{t}=2.1 \mathrm{~min}$; (III) 3 -metoxypuerarin, $\mathrm{t}=2.3 \mathrm{~min}$; (IV) 6-O-D-xylosylpuerarin, $\mathrm{t}=2.9 \mathrm{~min}$; $(\mathrm{V})$ daidzin, $\mathrm{t}=3.6 \mathrm{~min}$; (VI) daidzein, $\mathrm{t}=14.4 \mathrm{~min}$.

Isoflavone contents determined by the KU chromatogram are gathered in Table 1.

It was found that PUE constituted $13.3 \%$ of the compounds tested, while its derivatives 3'-hydroxypuerarin, 3'-methoxypuerarin and 6"-O-D-xylosylpuerarin measured approximately four times smaller $(2.31 \%, 2.89 \%$, and $2.55 \%$, respectively). The remaining isoflavones, i.e., DAI and daidzein, were rated $2.88 \%$ and $0.74 \%$, respectively. 
Table 1. Content of isoflavones in KU.

\begin{tabular}{ccc}
\hline No. & Compound & Concentration $[\mathbf{m g} / \mathbf{g}]$ \\
\hline I & $3^{\prime}-$ hydroxypuerarin & $23.1 \pm 2.0$ \\
\hline II & puerarin & $133.3 \pm 11$ \\
\hline III & $3^{\prime}-$ methoxypuerarin & $28.9 \pm 3.0$ \\
\hline IV & $6^{\prime \prime}-\mathrm{O}-\mathrm{D}-$ xylosylpuerarin & $25.5 \pm 3.0$ \\
\hline V & daidzin & $28.8 \pm 5.0$ \\
\hline VI & daidzein & $7.40 \pm 3.0$ \\
\hline
\end{tabular}

Mean \pm SD $(n=5)$.

\subsection{KU Repeated Administration Effects on Alcohol Drinking Behavior and Ghrelin Levels}

In this experiment, the effect of repeated intragastric (p.o.) KU administration $(28 \times)$ at a dose of $500 \mathrm{mg} / \mathrm{kg}$ on the amount of $\mathrm{EtOH}$ intake by Wistar rats $(n=36)$ was observed. The rats were previously divided into alcohol-preferring (PR; $n=18)$ and non-preferring $(\mathrm{NP} ; n=18)$ groups. Subsequently, they were divided randomly into four groups containing nine animals each (NP_MC, NP_KU, PR_MC, PR_KU).

Based on the obtained data on drinking behavior, there was a significant variability between the groups (ANOVA: $\mathrm{F}(3,28)=86.0 ; p=0.0000$ ). Further statistical analysis showed that control preferring animals (PR_MC) drank much more alcohol than control non-preferring rats $\left(\mathrm{NP} \_\mathrm{MC}\right)(p<0.01)$ (Figure 3A). The administration of KU significantly reduced the amount of EtOH consumed by alcohol preferring rats (PR_KU) in relation to the PR_MC group $(p<0.001)$. A similar significant effect was observed in non-preferring animals (NP_KU) in relation to NP_MC $(p<0.01)$ (Figure 3A).

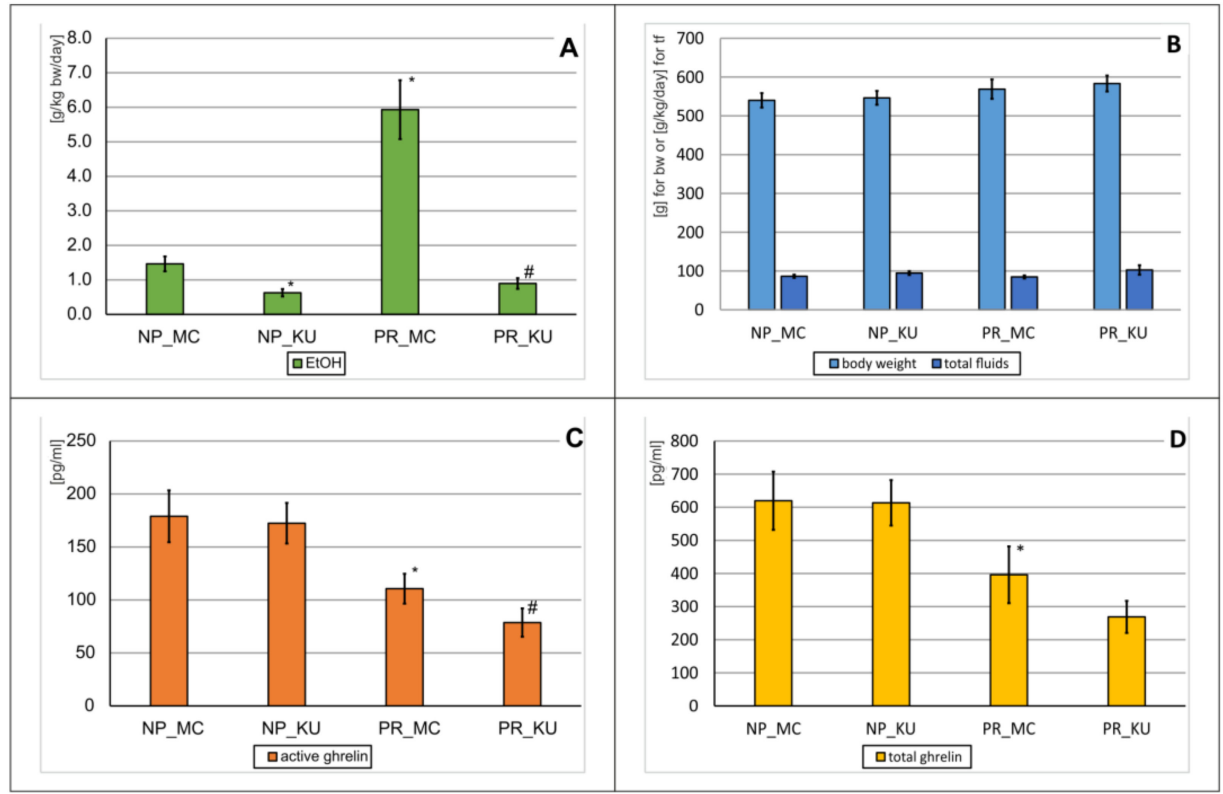

Figure 3. The effect of repeated $(28 \times)$ Pueraria lobata root extract $(\mathrm{KU})(500 \mathrm{mg} / \mathrm{kg}$, p.o.) administration on alcohol drinking behavior, total fluid intake, body weight and ghrelin levels in preferring (PR) and non-preferring (NP) rats. Legend: $n=8-9$; mean \pm SEM; PR_MC—control PR rats; NP_MC — control NP rats; MC—vehicle (0.5\% methylcellulose); (A) amount of drunk ethanol [g/ $\mathrm{kg} /$ day]; *—vs. NP_MC group, $p<0.01$; \#—vs. PR_MC group, $p<0.001$; (B) body weight $[\mathrm{g}]$ and the total amount of fluids intake $[\mathrm{g} / \mathrm{kg} /$ day]; (C) serum active ghrelin levels [pg $/ \mathrm{mL}] ;{ }^{*}$ - vs. NP_MC group, $p<0.05$; \#—vs PR_MC $p<0.05 ;$ (D) serum total ghrelin levels [pg/mL]; ${ }^{*}$-vs. NP_MC group, $p<0.05$.

The conducted experiment did not significantly affect the condition of the animals (Figure 3B) as there was no significant variation in their body mass (ANOVA: $F(3,28)=0.92$; 
$p=0.4414$ ) nor was there any difference in the amount of total fluid intake (ANOVA: $\mathrm{F}(3,28)=0.65 ; p=0.5857)$.

In this experiment, the effect of KU on ghrelin level was also examined in PR and NP groups. There was significant intergroup variability both for active ghrelin concentrations (ANOVA: $\mathrm{F}(3,28)=5.11 ; p=0.0060)$ and for total ghrelin levels (ANOVA: $\mathrm{F}(3,28)=4.96$; $p=0.0069)$. Further statistical analysis showed that in the animals preferring to drink $\mathrm{EtOH}$, the level of active ghrelin was significantly reduced (PR_MC vs. NP_MC), $p<0.05$ ) (Figure 3C). In preferring animals, after $\mathrm{KU}$ administration, even lower concentrations of active ghrelin were observed (PR_KU vs. PR_MC, $p<0.05$ ) (Figure 3C). Similarly, the level of total ghrelin was lower in PR rats when compared with NP animals (PR_MC vs. NP_MC, $p<0.05$ ) (Figure 3D). However, KU administration to preferring animals decreased the levels of total ghrelin in blood, but the difference between the obtained values for the study group and the control animals did not reach statistical significance (PR_KU vs. PR_MC, $p>0.05$ ). Such an effect was not found in NP rats (NP_KU vs. NP_MC, $p>0.05$ ) (Figure 3D).

\subsection{DAI Repeated Administration Effects on Alcohol Drinking Behavior and Ghrelin Levels}

In this experiment, the effect of repeated $(28 \times)$ intragastric (p.o.) administration of DAI at a dose of $40 \mathrm{mg} / \mathrm{kg}$ on the amount of EtOH consumed in Wistar rats $(n=36)$ was observed. The rats were previously divided into alcohol-preferring (PR; $n=18)$ and non-preferring (NP; $n=18)$ groups. Later, they were divided randomly into four groups containing nine animals each (NP_MC, NP_DAI, PR_MC, PR_DAI). Based on the obtained data on drinking behavior, there was a significant variability between the groups (ANOVA: $\mathrm{F}(3,34)=7.13 ; p=0.0008)$. Further analysis showed that PR_MC animals drank significantly more alcohol compared to NP_MC rats $(p<0.001)$ (Figure 4A). The administration of DAI to PR rats (PR_DAI) resulted in a significant reduction in the amount of EtOH consumed in relation to the proper control group (PR_MC) $(p<0.001)$ (Figure 4A). However, there was no effect of DAI on alcohol consumption in NP animals (NP_DAI vs. NP_MC, $p>0.05$ ).

The experiment did not significantly affect the condition of the animals (Figure 4B), because there was no significant variation in the weight of the animals (ANOVA: $F(3,34)=1.64$; $p=0.1969$ ), nor was there any difference in the amount of total fluid intake (ANOVA: $\mathrm{F}(3,34)=1.15 ; p=0.3450)$.

The effect of DAI on ghrelin levels in NP and PR rats was also investigated. There was a significant variability in the levels of both active (ANOVA: $\mathrm{F}(3,34)=6.49 ; p=0.0015$ ) and total ghrelin (ANOVA: $\mathrm{F}(3,34)=9.41 ; p=0.0001)$. Further statistical analysis showed that PR rats (PR_MC) had much lower concentrations $(p<0.001)$ of both active (Figure $4 C)$ and total (Figure 4D) ghrelin compared to NP (NP_MC) animals. The administration of DAI to PR rats increased the concentrations of both forms of ghrelin $(p<0.001)$, leading to the values observed in NP_MC rats (Figure 4C,D). However, the isoflavonoid did not change the concentration of both total and active ghrelin in NP animals.

\subsection{PUE Repeated Administration Effects on Alcohol Drinking Behavior and Ghrelin Levels}

In this experiment, the effect of repeated $(28 \times)$ intragastric (p.o.) administration of PUE at a dose of $150 \mathrm{mg} / \mathrm{kg}$ on the amount of EtOH drank in Wistar rats $(n=44)$ was observed. The rats were previously divided into preferring alcohol drinking (PR; $n=22)$ and non-preferring $(\mathrm{NP} ; n=22)$ groups. Later, they were randomly divided into four groups containing 11 animals each (NP_MC, NP_PUE, PR_MC, PR_PUE).

On the basis of the obtained results, a statistically significant variability between the groups in the amount of drank EtOH was observed (ANOVA: $\mathrm{F}(3,40)=25.1 ; p=0.0000$ ). Further analysis showed that PR_MC animals consumed much more alcohol compared to NP_MC animals $(p<0.001)$ (Figure 5A). The administration of PUE to PR (PR_PUE) rats resulted in a significant reduction in the amount of EtOH consumed in relation to the PR_MC group $(p<0.001)$ (Figure 5A). However, no effect of PUE on alcohol consumption in NP animals was found (NP_PUE vs. NP_MC, $p>0.05$ ). 


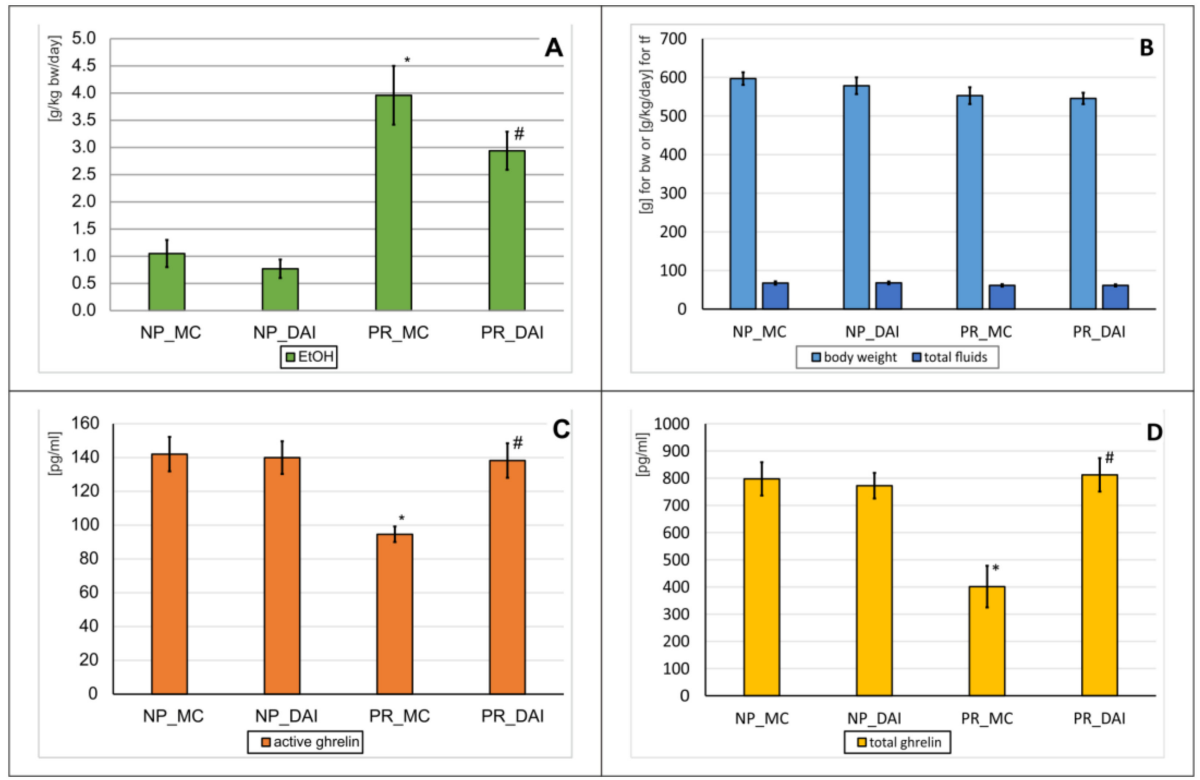

Figure 4. The effect of repeated $(28 \times)$ daidzin (DAI) $(40 \mathrm{mg} / \mathrm{kg}$, p.o.) administration on alcohol drinking behavior, total fluid intake, body weight, and ghrelin levels in preferring (PR) and nonpreferring (NP) rats. Legend: $n=8-9 ;$ mean \pm SEM; PR_MC—control PR rats; NP_MC—control NP rats; MC—vehicle (0.5\% methylcellulose); (A) amount of drunk ethanol [g/kg/day]; * -vs. NP_MC group, $p<0.001$; \#-vs. PR_MC group, $p<0.001$; (B) body weight $[\mathrm{g}]$ and the total amount of fluid intake $\left[\mathrm{g} / \mathrm{kg} /\right.$ day]; (C) serum active ghrelin levels [pg/mL]; ${ }^{*}$ - vs. NP_MC group, $p<0.001$; \#—vs. PR_MC, $p<0.001$; (D) serum total ghrelin levels [pg/mL]; ${ }^{*}$-vs. NP_MC group, $p<0.001$; \#-vs. PR_MC, $p<0.001$.

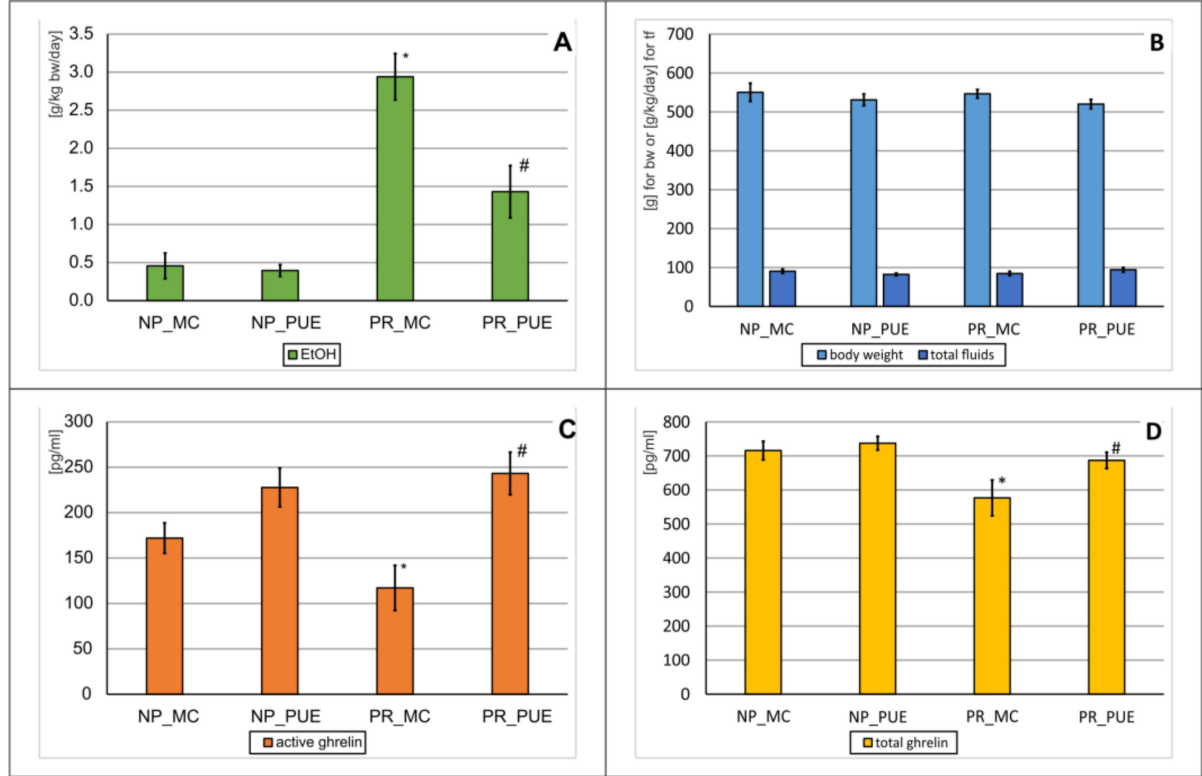

Figure 5. The effect of repeated $(28 \times)$ puerarin (PUE) $(150 \mathrm{mg} / \mathrm{kg}$, p.o.) administration on alcohol drinking behavior, total fluid intake, body weight, and ghrelin levels in preferring (PR) and nonpreferring (NP) rats. Legend: $n=9-11$; mean \pm SEM; PR_MC—control PR rats; NP_MC—control NP rats; MC—vehicle (0.5\% methylcellulose); (A) amount of drunk ethanol [g/kg/day]; * -vs. NP_MC group, $p<0.001$; \#-vs. PR_MC group, $p<0.001$; (B) body weight $[\mathrm{g}]$ and the total amount of fluid intake $[\mathrm{g} / \mathrm{kg} /$ day]; (C) serum active ghrelin levels $[\mathrm{pg} / \mathrm{mL}] ; *-\mathrm{vs}$. NP_MC group, $p<0.001$; \#—vs. PR_MC, $p<0.001$; (D) serum total ghrelin levels [pg/mL]; * -vs. NP_MC group, $p<0.001$; \#-vs. PR_MC, $p<0.001$. 
The experiment did not significantly affect the condition of the animals (Figure 5B), because no significant variation was found in the weight of animals (ANOVA: $F(3,40)=0.69$; $p=0.5589$ ) or in the total fluid intake (ANOVA: $\mathrm{F}(3,40)=1.11 ; p=0.3573$ ).

In this experiment, the effect of PUE was also measured on active and total ghrelin levels in NP and PR rats (Figure 5C,D). On the basis of the obtained results, a statistically significant variability between the groups was observed for both active ghrelin (ANOVA: $\mathrm{F}(3,37)=6.96 ; p=0.0007)$ and a total one (ANOVA: $\mathrm{F}(3,34)=4.82 ; p=0.0066)$.

Furthermore, the statistical analysis revealed that PR_MC animals had significantly lower levels of active and total ghrelin $(p<0.001)$ relative to the corresponding NP_MC group (Figure 5C,D). The administration of PUE to PR animals (PR_PUE) increased the concentration of both forms of ghrelin in relation to PR_MC animals $(p<0.001)$ (Figure 5C,D). Such an effect of this isoflavonoid was not observed in NP_PUE rats in relation to NP_MC animals $(p>0.05)$.

\subsection{AC Repeated Administration Effects on Alcohol Drinking Behavior and Ghrelin Levels}

In another experiment, the effect of repeated $(28 \times)$ intragastric (p.o.) administration of $\mathrm{AC}$ at a dose of $500 \mathrm{mg} / \mathrm{kg}$ on the amount of EtOH consumed in Wistar rats $(n=36)$ was observed. The rats were previously divided into preferring alcohol drinking (PR; $n=18)$ and non-preferring (NP; $n=18)$ groups. Later, they were randomly divided into four groups containing nine animals each (NP_MC, NP_AC, PR_MC, PR_AC).

It was observed that AC significantly influenced the variability of the amount of EtOH consumed (ANOVA: $\mathrm{F}(3,30)=10.8 ; p=0.0001)$. Further analysis showed that PR_MC animals drank much more alcohol compared to NP_MC animals $(p<0.001)$ (Figure 6A). AC administration significantly reduced the EtOH consumption in preferring animals (PR_AC) when compared to the PR_MC group $(p<0.001)$ (Figure 6A); in NP rats, no significant reduction in EtOH intake was observed (NP_AC vs. NP_MC, $p>0.05$ ). At the same time, it was found that the administration of $\mathrm{AC}$ did not affect the condition of the animals in this experiment (Figure 6B), because there was no variation in the weight of the animals (ANOVA: $\mathrm{F}(3,30)=0.316 ; p=0.8196$ ) or the total fluid intake (ANOVA: $\mathrm{F}(3,30)=0.226 ; p=0.8773$ ).

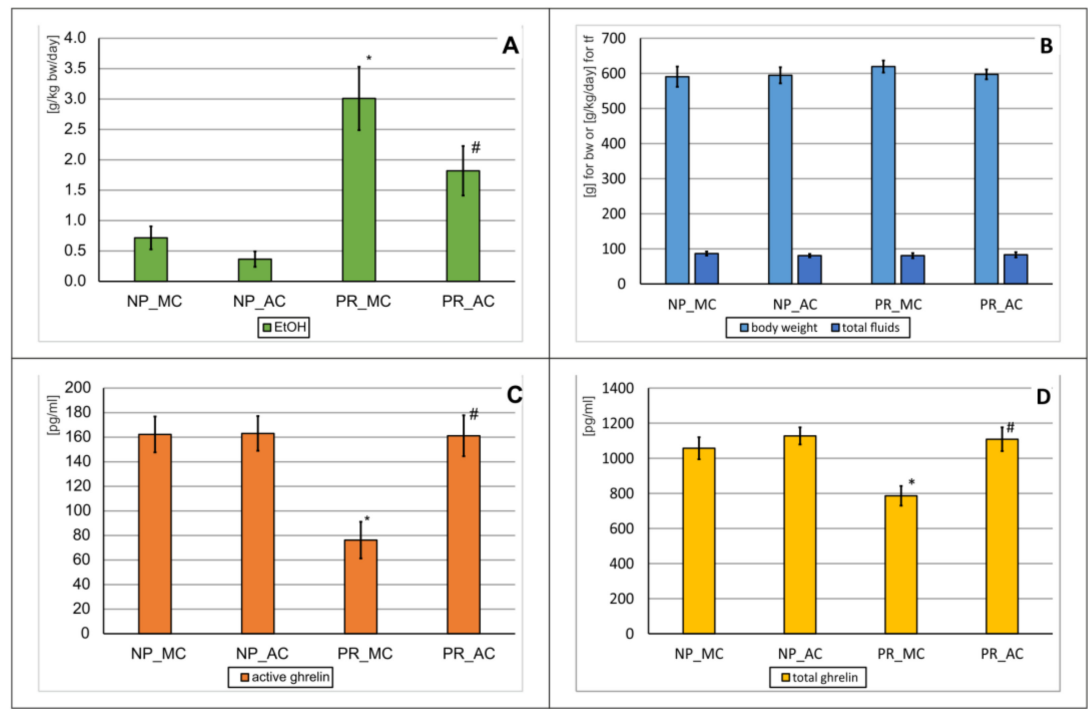

Figure 6. The effect of repeated $(28 \times)$ acamprosate $(\mathrm{AC})(500 \mathrm{mg} / \mathrm{kg}$, p.o.) administration on alcohol drinking behavior, total fluid intake, body weight, and ghrelin levels in preferring (PR) and nonpreferring (NP) rats. Legend: $n=7-10$; mean \pm SEM; PR_MC—control PR rats; NP_MC—control NP rats; MC—vehicle (0.5\% methylcellulose); (A) amount of drunk ethanol [g/kg/day]; ${ }^{*}$ vs. NP_MC group, $p<0.001$; \#-vs. PR_MC group, $p<0.001$; (B) body weight $[\mathrm{g}]$ and the total amount of fluid intake $\left[\mathrm{g} / \mathrm{kg} /\right.$ day]; (C) serum active ghrelin levels [pg/mL]; ${ }^{*}$-vs. NP_MC group, $p<0.001$; \#—vs. PR_MC, $p<0.001$; (D) serum total ghrelin levels [pg/mL]; *-vs. NP_MC group, $p<0.001$; \#-vs. PR_MC, $p<0.001$. 
In the same experiment, it was found that $\mathrm{AC}$ administration significantly influenced the variability of the obtained results for active (ANOVA: $\mathrm{F}(3,30)=8.05 ; p=0.0006$ ) and total ghrelin levels (ANOVA: $\mathrm{F}(3,30)=6.87 ; p=0.0011$ ). The level of active ghrelin, significantly lowered by alcohol consumption in PR rats (PR_MC vs. NP_MC; $p<0.001)$, increased to the control value (observed in NP rats) by AC administration $(p<0.001)$ (Figure 6C,D). Similarly, AC administration caused an increase in the level of total ghrelin in PR animals (AC_PR) when compared with the PR_MC group $(p<0.001)$. Such an effect was not seen in NP rats.

\subsection{NAL Repeated Administration Effects on Alcohol Drinking Behavior and Ghrelin Levels}

In the next experiment, the effect of repeated $(28 \times)$ intraperitoneal (i.p.) administration of NAL at a dose of $0.1 \mathrm{mg} / \mathrm{kg}$ on the amount of EtOH consumed in Wistar rats $(n=28)$ was observed. The rats were previously divided into preferring alcohol drinking (PR; $n=14)$ and non-preferring (NP; $n=14$ ) groups. Later, they were randomly divided into four groups containing seven animals each (NP_H $\mathrm{H}_{2} \mathrm{O}, \mathrm{NP} \_\mathrm{NAL}, \mathrm{PR} \_\mathrm{H}_{2} \mathrm{O}, \mathrm{PR} \_\mathrm{NAL}$ ).

It was observed that NAL significantly influenced the variability of the amount of EtOH consumed (ANOVA: $\mathrm{F}(3,28)=13.3 ; p=0.0000$ ). Further analysis showed that PR_H $\mathrm{H}_{2} \mathrm{O}$ animals drank much more alcohol compared to $\mathrm{NP}_{-} \mathrm{H}_{2} \mathrm{O}$ animals $(p<0.001)$ (Figure 7A). The administration of NAL reduced the amount of EtOH consumed by preferring animals (PR_NAL) compared to the control preferring rats $\left(\mathrm{PR} \_\mathrm{H}_{2} \mathrm{O}, p<0.001\right)$, whereas the drug did not affect the alcohol intake in NP animals (NP_NAL vs. NP_H ${ }_{2} \mathrm{O}, p>0.05$ ) (Figure 7A).

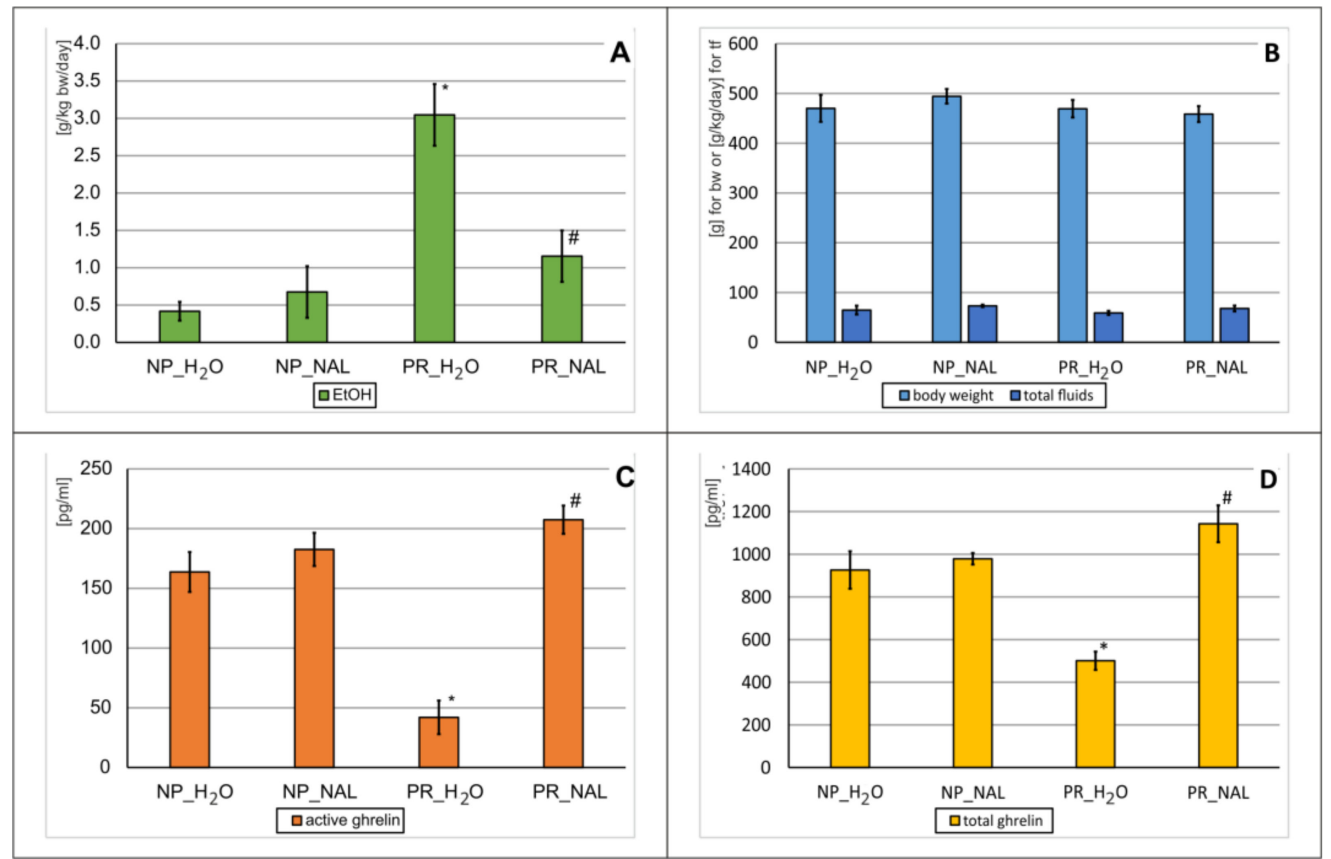

Figure 7. The effect of repeated $(28 \times)$ naltrexone (NAL) $(0.1 \mathrm{mg} / \mathrm{kg}$, i.p.) administration on alcohol drinking behavior, total fluid intake, body weight, and ghrelin levels in preferring (PR) and nonpreferring (NP) rats. Legend: $n=7$; mean \pm SEM; PR_H $\mathrm{H}_{2} \mathrm{O}$-control PR rats; $\mathrm{NP}_{-} \mathrm{H}_{2} \mathrm{O}$-control NP rats; $\mathrm{H}_{2} \mathrm{O}$-vehicle (water for injection); (A) amount of drunk ethanol $\left[\mathrm{g} / \mathrm{kg} /\right.$ day]; ${ }^{*}$ - vs. $\mathrm{NP}_{-} \mathrm{H}_{2} \mathrm{O}$ group, $p<0.001$; \#-vs. PR_H $\mathrm{H}_{2} \mathrm{O}$ group, $p<0.001$; (B) body weight $[\mathrm{g}]$ and the total amount of fluid intake [g/kg/day]; (C) serum active ghrelin levels [pg/mL]; ${ }^{*}-\mathrm{vs}$. $\mathrm{NP}_{-} \mathrm{H}_{2} \mathrm{O}$ group, $p<0.001$; $\#$ \#-vs. PR_H ${ }_{2} \mathrm{O}, p<0.001$; (D) serum total ghrelin levels [pg/mL]; ${ }^{*}$-vs. NP_H $\mathrm{H}_{2} \mathrm{O}$ group, $p<0.001$; \#-vs. PR_H ${ }_{2} \mathrm{O}, p<0.001$.

At the same time, it was found that the administration of NAL did not change the condition of the animals in this experiment (Figure 7B), as there was no variation in the 
weight of the animals (ANOVA: $\mathrm{F}(3,28)=0.60 ; p=0.6208$ ), or the total fluid intake (ANOVA: $\mathrm{F}(3,28)=1.07 ; p=0.3789)$.

In this experiment, it was noted that the administration of NAL significantly influenced the changes in active (ANOVA: $\mathrm{F}(3,28)=30.7 ; p=0.0000$ ) and total ghrelin concentrations (ANOVA: $\mathrm{F}(3,28)=21.5 ; p=0.0000)$. Further analysis showed that NAL significantly affected and caused an increase in the levels of both forms of ghrelin in PR animals (PR_NAL) when compared with control preferring rats $\left(\mathrm{PR} \_\mathrm{H}_{2} \mathrm{O}, p<0.001\right)$, leading to values slightly higher than those observed in control NP animals $\left(\mathrm{NP}_{-} \mathrm{H}_{2} \mathrm{O}\right)$ (Figure 7C,D). Such an effect of NAL was not seen in NP animals.

\subsection{KU Effects on EtOH Tolerance Development and Ghrelin Levels}

This experiment was conducted in alcohol Warsaw high-preferring (WHP) rats. The effect of repeated once a day for 9 consecutive days $(9 \times)$ administration of $\mathrm{KU}(500 \mathrm{mg} / \mathrm{kg}$, p.o.) on the development of $\mathrm{EtOH}$ tolerance after repeated $(9 \times)$ administration of $\mathrm{EtOH}$ ( $3.0 \mathrm{~g} / \mathrm{kg}$, i.p.) in comparison to $\mathrm{H}_{2} \mathrm{O}$-treated animals was investigated. Selected rats $(n=32)$ were randomly divided into four groups containing eight animals each $\left(\mathrm{H}_{2} \mathrm{O} \_\mathrm{MC}\right.$, $\mathrm{H}_{2} \mathrm{O} \_\mathrm{KU}, \mathrm{Et} \_\mathrm{MC}$, Et_KU).

\subsubsection{EtOH Tolerance}

The aim of this experiment was to evaluate the effect of KU, measured in the 30th, 60th, 90th minute after the administration of $\mathrm{EtOH}(3 \mathrm{~g} / \mathrm{kg}$, i.p.), on changes in rectal rat temperature. It should be stressed that at the beginning of the experiment (time $\mathrm{t}=0$ ), the rats did not differ in their baseline rectal temperature $\left(38.2 \pm 0.07{ }^{\circ} \mathrm{C}\right.$; ANOVA: $\mathrm{F}(3,22)=1.92 ; p=0.1488)$. In the 30th, 60th, and 90th minute, while examining the changes in temperature under the influence of $\mathrm{KU}$ and $\mathrm{EtOH}$ administration, significant variabilities were found. The obtained results of statistical calculations were as follows: in the 30th minute (main effect-temperature change: $\mathrm{EtOH}$ and KU, ANOVA with replication: $\mathrm{F}(3,22)=40.0 ; p=0.0000)$; effect of 9-day consecutive EtOH administration, ANOVA with replication: $\mathrm{F}(3,66)=19.2 ; p=0.0000)$; interaction between main effect and sequential administration effect: ANOVA with replication: $\mathrm{F}(9,66)=5.03 ; p=0.0004)$, in 60th minute (main effect-temperature change: $\mathrm{EtOH}$ and $\mathrm{KU}$, ANOVA with replication: $\mathrm{F}(3,22)=57.4$; $p=0.0000$; effect of 9-day consecutive $\mathrm{EtOH}$ administration, ANOVA with replication: $\mathrm{F}(3,66)=12.41 ; p=0.0000$, interaction between main effect and sequential administration effect, ANOVA with replication: $\mathrm{F}(9,66)=7.73 ; p=0.0000$ ), in the 90th minute (main effecttemperature change: $\mathrm{EtOH}$ and $\mathrm{KU}$, ANOVA with replications: $\mathrm{F}(3,22)=15.7 ; p=0.0000$; effect of 9-day consecutive EtOH administration, ANOVA with replications: $\mathrm{F}(3,66)=12.1$; $p=0.0000$, interaction between main effect and sequential administration effect (ANOVA with replications: $\mathrm{F}(9,66)=5.29 ; p=0.0000)$.

Further statistical analysis, using the post hoc test, showed that on the first day, significant differences $(p<0.001)$ between the Et_MC and $\mathrm{H}_{2} \mathrm{O} \_\mathrm{MC}$ groups were found when measuring the temperature in the $30^{\text {th }}, 60^{\text {th }}$, and $90^{\text {th }}$ minute after EtOH administration (Figure $8 \mathrm{~A}-\mathrm{C}$ ). Moreover, on the third day of the experiment, there was also a significant difference between Et_MC and $\mathrm{H}_{2} \mathrm{O} \_\mathrm{MC}$ in the 60th minute $(p<0.001)$ (Figure 8B). On the remaining days, i.e., the fifth and eighth days, for all time points and on the third day (30 and $90 \mathrm{~min}$ after $\mathrm{EtOH}$ administration), the measured temperature differences between the groups receiving $\mathrm{EtOH}$ and $\mathrm{H}_{2} \mathrm{O}$ did not reach statistical significance (Figure 8A,C). When examining the effect of $\mathrm{KU}$ administration, it was found that in the animals from the Et_KU group, in the 30th minute on days three, five and eight, the body temperature was significantly lower than in the Et_MC group $(p<0.0001)$ (Figure $8 \mathrm{~A})$. A similar effect was observed for the measurement in the 60th minute (Figure 8B), where a statistically significant difference was recorded already on the first day of measurement and remained significant on all following days vs. the Et_MC group $(p<0.0001)$. In the 90th minute, the KU effect weakens and is significant only on the third and fifth days in relation to the Et_MC group $(p<0.0001)$ (Figure 8C). 


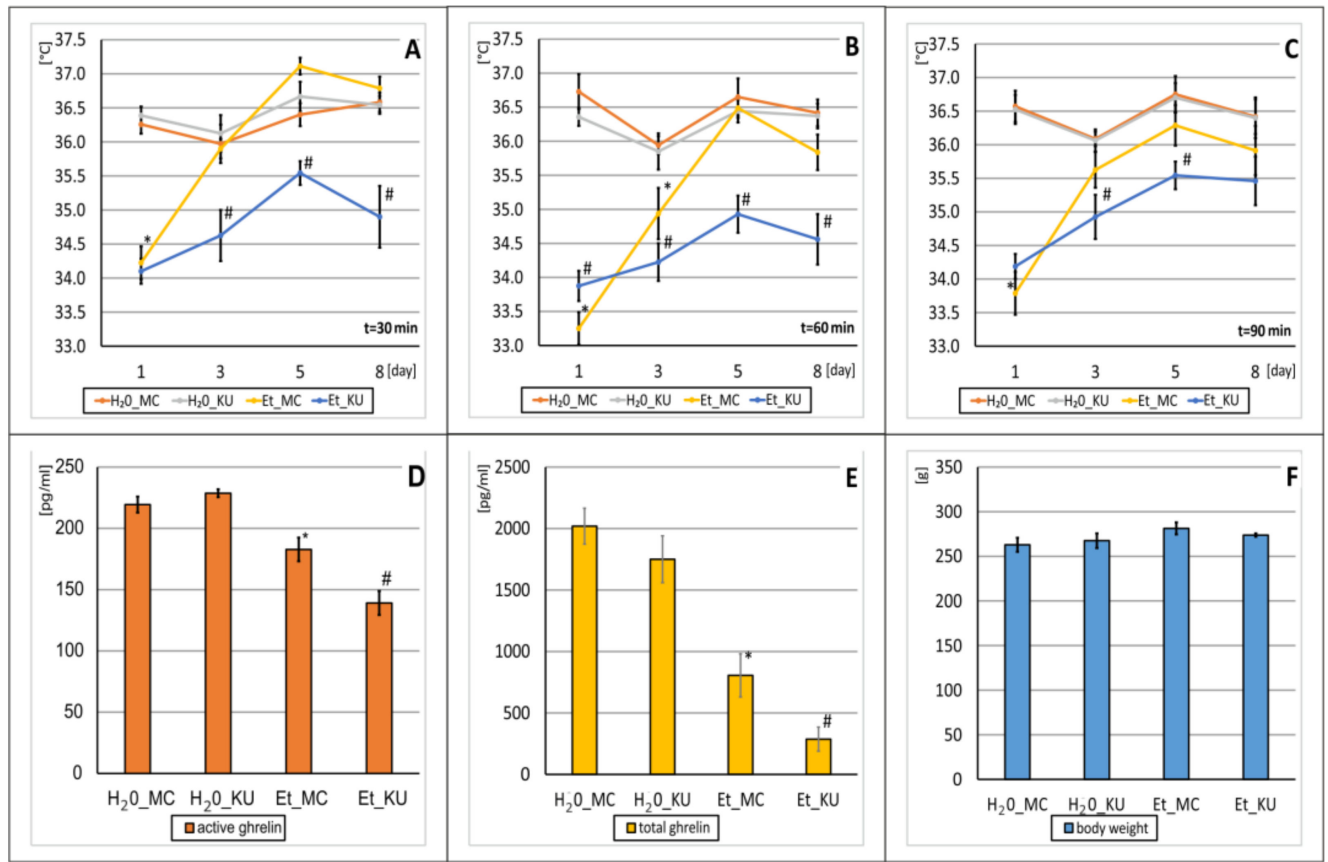

Figure 8. The effect of repeated once a day for 9 days $(9 \times)$ Pueraria lobata root extract (KU) (500 mg/kg, p.o.) administration on ethanol (3.0 g/ kg/day, i.p.) tolerance development, ghrelin levels, and body weight in alcohol Warsaw High-Preferring (WHP) rats. Legend: $n=6-8$; mean \pm SEM; MC-0.5\% methylcellulose; Et-30\% ethanol; $\mathrm{H}_{2} \mathrm{O} \_\mathrm{MC}$-absolute control group; Et_MC-positive control group; (A) Temperature $\left[{ }^{\circ} \mathrm{C}\right]$ in rat $30 \mathrm{~min}$ after EtOH administration; *-vs. $\mathrm{H}_{2} \mathrm{O} \_\mathrm{MC}$ group, $p<0.0001$; \#-vs. EtOH_MC group, $p<0.0001$; (B) Temperature [ $\left.{ }^{\circ} \mathrm{C}\right]$ in rat 60 min after EtOH administration *—vs. $\mathrm{H}_{2} \mathrm{O} \_\mathrm{MC}$ group, $p<0.0001$; \#-vs. EtOH_MC group, $p<0.0001$; (C) Temperature $\left[{ }^{\circ} \mathrm{C}\right]$ in rat 90 min after EtOH administration *-vs. $\mathrm{H}_{2} \mathrm{O} \_\mathrm{MC}$ group, $p<0.0001$; \#-vs. EtOH_MC group, $p<0.0001$; (D) Serum active ghrelin levels [pg/mL]; *-vs. H $\mathrm{H}_{2} \mathrm{O} \_\mathrm{MC}$ group, $p<0.05$; \#-vs. Et_MC, $p<0.001$; (E) Serum total ghrelin levels [pg/mL]; *—vs. $\mathrm{H}_{2} \mathrm{O} \_\mathrm{MC}$ group, $p<0.001$; \#-vs. Et_MC, $p<0.001$. (F) Body weight $[\mathrm{g}]$.

Summarizing, $30 \mathrm{~min}$ after EtOH administration, the body temperature of animals treated with $\mathrm{EtOH}\left(\mathrm{Et} \_\mathrm{MC}\right)$ decreased compared to the absolute control group $\left(\mathrm{H}_{2} \mathrm{O} \_\mathrm{MC}\right)$, whereas in the group receiving only $\mathrm{KU}\left(\mathrm{H}_{2} \mathrm{O} \_\mathrm{KU}\right)$, there was no effect on temperature of $\mathrm{KU}$ alone (vs. $\mathrm{H}_{2} \mathrm{O} \_\mathrm{MC}$ ), while the effect in the Et_KU group is clearly marked (Figure 8A). Similarly, $60 \mathrm{~min}$ after EtOH administration there is still a body temperature decrease in Et_MC animals compared to the control group $\left(\mathrm{H}_{2} \mathrm{O} \_\mathrm{MC}\right)$; for the Et_KU group the effect of the temperature drop remains strongly marked (Figure 8B). Moreover, 90 min after the $\mathrm{EtOH}$ administration, the body temperature also remained lower than in the control group $\left(\mathrm{H}_{2} \mathrm{O} \_\mathrm{MC}\right)$, and the values for the Et_KU group, as in the previous time intervals, remained the lowest (Figure 8C).

\subsubsection{Ghrelin Levels}

In the experiment, significant group variability was also observed both for the active (ANOVA: $\mathrm{F}(3,22)=5.36 ; p=0.007$ ) (Figure 8D) and total ghrelin levels (ANOVA: $\mathrm{F}(3,22)=20.5 ; p=0.0000$ ) (Figure $8 \mathrm{E}$ ). The post hoc analysis showed that after 9 days of EtOH administration in the Et_MC group, a significant decrease in the active $(p<0.05)$ and total $(p<0.001)$ ghrelin values in relation to the $\mathrm{H}_{2} \mathrm{O} \_\mathrm{MC}$ group was observed. In the group of animals receiving both EtOH and $\mathrm{KU}$ (Et_KU), a strong, statistically significant decrease in the level of active and total ghrelin was found in comparison to the control animals from the Et_MC group $(p<0.001)$ (Figure 8D,E). 


\subsubsection{Body Weight}

At the same time, it was noticed that the experiment did not significantly affect the body weight of the animals used (ANOVA: $\mathrm{F}(3,27)=1.46 ; p=0.2480$ ) (Figure $8 \mathrm{~F}$ ).

\section{Discussion}

\subsection{EtOH Intake}

In this study, the results of five independent experiments related to the administration of KU, PUE, DAI, AC, and NAL on ghrelin levels in a selected model of free-choice alcohol consumption by rats were analyzed. This study was based on the assumption that the models of increased free-choice alcohol consumption would be used, obtained in Wistar animals using the induction model previously modified [47]. The introduction of this model and, especially, the induction and withdrawal syndrome that lasted 14 days, resulted in the appearance of a clear reflex of preference and led to the emergence of two extreme groups in terms of EtOH preferences: rats named non-preferring (NP) and preferring (PR) to drink alcohol by free choice, with significant differences in the amounts of consumed $\mathrm{EtOH}$. This is consistent with the conclusions of other authors who emphasized that the use of such a procedure, especially the 14-day interval, allows to obtain the above mentioned NP and PR rats [47,54-56]. Two withdrawal periods, used in the experiments during which the rats only drank water, mimics the human pattern of drinking alcohol, due to the fact that an increased percentage of preference animals consumed significant amounts of alcohol [57,58]. In our model, approximately $20 \%$ of animals drank high amounts of $\mathrm{EtOH}$ and $20 \%$ drank small amounts. This is consistent with numerous studies which found rats to be rather resistant to alcohol addiction [58-61].

In drug-related studies on animals drinking alcohol, $\mathrm{AC}$ in a dose of $500 \mathrm{mg} / \mathrm{kg}$, p.o. was used $(28 \times)$, as in previous studies [62]. AC was used here as a standard drug with a recognized anti-alcohol effect [63-69], although the exact mechanism of its action is still under investigation [70,71]. As a result of the drug activity, free-choice alcohol consumption was reduced by $30 \%$ in PR rats, as compared to the corresponding control animals that did not receive the drug. Thus, the effectiveness of AC under model conditions was confirmed, which is consistent with other studies [62,72,73]. In a subsequent experiment, NAL was repeatedly administered $(28 \times)$ per dose $0.1 \mathrm{mg} / \mathrm{kg}$, i.p., to NP and PR rats, also as in our previous studies [74]. The effect of this standard drug on the drinking reflex was observed, and it was found that in the group of PR animals the amount of EtOH consumed decreased threefold compared to the placebo group, which is in line with other studies and human observations [75-77].

Kudzu - a raw material of plant origin, used in the present study as an extract (KU), is by its nature a mixture of various chemical compounds $[78,79]$. The use of kudzu as a substance of plant origin is noted in traditional medicine, as well as in more recent studies $[10,17,80]$. The isoflavonoids are the compounds that primarily determine the anti-alcoholic pharmacological activity of KU. Knowing the composition of the extract (Table 1), it was essential to verify whether the effect observed after the administration of $\mathrm{KU}$ alone, on drinking alcohol in free-choice procedure, would be similar to the effects of the isolated compounds, e.g., DAI and PUE, administered in separate experiments. The extract used in this study, with the content of PUE and DAI, was similar to one applied by other authors (in their studies on the influence of $\mathrm{KU}$ on the alcohol drinking behavior of rats) who administered KU with contents of $150 \mathrm{mg} / \mathrm{g}$ of PUE and $13 \mathrm{mg} / \mathrm{g}$ of DAI [79]. In our study, KU was administered in a dose of $500 \mathrm{mg} / \mathrm{kg}$, p.o., for 28 days, according to data from other studies [78,81], where the authors noticed that $\mathrm{KU}$ in this dose significantly reduced the amount of alcohol drunk without affecting the total fluid intake or inducing weight changes. However, they also found that higher doses of KU (750 and $1000 \mathrm{mg} / \mathrm{kg}$ ) did not result in a stronger effect on the alcohol reflex test but lowered the total amount of fluids consumed [78].

The free-choice alcohol drinking performance of KU-treated animals showed clear changes, expressed by a sixfold reduction in the amount of alcohol consumed by PR rats 
(PR_KU) when compared to vehicle-treated animals (PR_MC). It was consistent with the results of studies by other authors in which KU had a strong ability to inhibit the drinking reflex $[10,78,80-82]$. However, the KU mechanism of action is not obvious, since there were some observations that the isoflavones from KU suppressed alcohol drinking without entering the brain [78] and none of the compounds changed the activities of liver alcohol dehydrogenase $(\mathrm{ADH})$ and aldehyde dehydrogenase (ALDH) [15]. On the contrary, the data shows that KU ( $P$. lobata root extract produced in a special way called PLF) intravenous administration in doses of 80 and $160 \mathrm{mg} / \mathrm{kg}$ resulted in an occurrence (among others) of PUE in the brain, using an LC-MS/MS method in micro dialysate from striatal extracellular fluid of rats [83]. These authors also suggested that KU, especially in a lower dose (so-called optimal), promoted dopamine metabolism and inhibited serotonin metabolism without an influence on glutamine level. As for KU's peripheral mechanism of action, there is also data showing that PUE (in a very high dose of $500 \mathrm{mg} / \mathrm{kg}$, p.o.) can elevate ADH activity [84] and/or DAI can inhibit a mitochondrial type 2 aldehyde dehydrogenase action (ALDH-2) [14]. Hence, it can be inferred that the mechanism of KU activity requires further detailed exploration and clarification.

In the experiment on the influence of DAI on the drinking reflex, a dose of $40 \mathrm{mg} / \mathrm{kg}$, p.o. was applied. It was found that repeated administration of DAI $(28 \times)$ reduced the amount of alcohol drunk by about $20 \%$ in animals belonging to the PR group, which suggests that DAI has an inhibitory effect on drinking $\mathrm{EtOH}$ in a free-choice procedure. It is known that the bioavailability of DAI administered per se is about 10 times lower than that administered in the same dose in the form of P. lobata root extract. Therefore, in our experiment, the dose of this compound was slightly higher than that, resulting directly from the mathematical calculation of the content in the investigated extract, also taking into account that DAI may have a reduced bioavailability $[10,82]$. Hence, the average dose of this flavonoid was chosen out of those used by other authors [85], knowing that the DAI administration at a much higher dose on the amount of alcohol drunk by rats (100 mg/kg, p.o.) [16] did not differ from our results in the applied dose. Moreover, in some studies DAI (30 mg/kg, p.o.) was administered in the form of pellets with the diet, although this procedure could cause an increase in bioavailability of this isoflavonoid [15]. Regardless of the above, it was also suggested that the diet had no effect on the activity of DAI as the substance reducing the EtOH consumption in animals [86].

PUE was the second isoflavonoid investigated for the effect of drinking EtOH in the free-choice procedure. The dose of this compound $(150 \mathrm{mg} / \mathrm{kg}$, p.o.) was selected on the basis of data from the literature $[15,34,79,81]$, taking into account the typical percentage of isoflavonoids in the raw root material [87] and in different $P$. lobata extracts [84,88]. PUE was administered for 28 days according to the same schedule as the other substances used in our experiments. The obtained data showed that repeated administration of PUE decreased by half the amount of alcohol drunk in the PR control group (PR_MC), which is consistent with the results of other authors $[15,79,81]$.

Summarizing, the analysis of our research on the use of KU, DAI, and PUE, as potential compounds with the effect of reducing alcohol drinking, showed that the strongest effect is produced by $\mathrm{KU}$, which reduced $\mathrm{EtOH}$ drinking sixfold, while DAI and PUE yielded only $20 \%$ and $50 \%$ reductions, respectively. These observations suggest that it is not only the activity of the isoflavonoids present in KU that is responsible for the action of reducing drinking, as previously shown $[15,81]$, but also other substances found in the extract, which may facilitate the absorption of DAI and PUE as active compounds, and/or influence the extract's properties through other mechanisms. The verification of this hypothesis requires more in-depth investigation.

\subsection{Tolerance}

In our study on the alcohol tolerance development in WHP animals, daily intraperitoneal administration of $\mathrm{EtOH}(3 \mathrm{~g} / \mathrm{kg} /$ day) led to noticeably rapid development, the effect already found on the third day of the experiment. This is in line with our previous similar 
experiments on Wistar animals [89-91]. Since KU induced lowering of EtOH consumption (see Section 2.7.1), it was decided to check its possible influence on the alcohol tolerance development. It was found that KU inhibited the development of EtOH tolerance, which was most apparently observed $60 \mathrm{~min}$ after the alcohol administration. The obtained results of this KU action are very interesting, especially because the development of such tolerance often precedes or accompanies the development of the alcohol addiction process [92,93]. Therefore, this profile of KU activity is crucial, and may constitute an option for its preventive use in groups of patients with an increased risk of alcoholism.

\subsection{Ghrelin Level}

In all experiments with the prolonged treatment with KU, DAI, PUE, AC, and NAL it was shown that only EtOH drinking produced a decline in both active and total ghrelin level, especially in PR rats. The nature of the relationship between ghrelin and alcohol is complex. However, as already mentioned in the introduction, drinking alcohol reduces the level of this peptide in the blood in humans [51,52] and in animal models, as was the subject of our previous research [47] and which was also shown in this work. This correlated with increased GHS-R1A gene expression in nucleus accumbens, ventral tegmental area, amygdala, prefrontal cortex, and hippocampus in AA rats $[43,94]$. However recently, it was found that alcohol does not act directly with the ghrelin system, although alcohol decreases peripheral ghrelin concentrations in vivo (also in humans), but not in proportion to alcohol's caloric value or through direct interaction with ghrelin-secreting gastric mucosal cells, the ghrelin receptor, or the ghrelin-O-acyltransferase (GOAT) enzyme [95]. On the other hand, the administration of exogenous ghrelin has a more complex nature, as it leads to an increased alcohol supply since it has been proven in alcoholics who experienced increases in alcohol self-administration after administration of ghrelin in the form of an infusion [96]. However, further considerations in this field go beyond the scope of this work.

Repeated AC administration led to compensating for the above observation by increasing the level of ghrelin to the values found in control animals (NP). The mechanism by which the studied drug may alter ghrelin levels remains to date is still unknown. It is proven that blocking the NMDA receptor in the mesolimbic system (VTA) inhibits the increase in motor activity of animals observed after ghrelin administration [44]. However, it is unclear to what extent this mechanism is related to the effects of AC on the levels of both forms of ghrelin in our study. It was found that changes in ghrelin levels were noticeably inversely related to the amount of alcohol drunk by PR animals, which is in line with other observations $[36,47]$. While the exact mechanism of this relationship is unclear, it appears to be mainly due to the amount of available alcohol consumed by the PR rats. It is true that AC can lower the expression of the ghrelin gene in mice in the frontal cortex [97], but these studies were conducted without alcohol, hence the conclusions drawn from them cannot be easily applied to the studies in our work.

In the course of the study on the NAL influence on the free-choice alcohol drinking reflex in NP and PR rats, it was found that the drug had a normalizing effect on the reduced values of both ghrelin forms in PR rats, which was not observed in NP animals. This effect, as in the case of AC administration, is inversely related to the amount of alcohol drunk in the conditions of EtOH choice by PR animals. The nature of NAL's effect on the increase in ghrelin levels, with the simultaneous abolition of alcohol drinking, is probably related to the action of alcohol itself. However, more complicated mechanisms related to the action of the ghrelin receptor on the activity of POMC and CART-peptides involved in the development of addiction - cannot be ruled out [98]. Nevertheless, it is not clear how ghrelin excites POMC neurons since there is some data suggesting that this phenomenon occurs in a different way than via activation of the ghrelin receptor coupled with excitation of agouti-related protein/neuropeptide Y [99].

In another experiment, PR and NP animals were given long-term KU. It was found that, unlike other substances, $\mathrm{KU}$ in the presence of $\mathrm{EtOH}$ does not bring the ghrelin levels 
to the control values but to a further decrease in their values. Similarly, the experiment on induction of alcohol tolerance, and after nine KU administrations, caused an intensification of the decrease in ghrelin levels in relation to the group receiving $\mathrm{EtOH}$ alone. The observation of the group receiving only $\mathrm{KU}$ (without $\mathrm{EtOH}$ ) showed no decrease in the level of ghrelin. It can be assumed that this situation might have been caused by the caloric value of the extract, as KU was not a pure, active chemical but an alcoholic plant extract consisting of fats, proteins and carbohydrates, the administration of which causes a reduction in ghrelin levels [100]. However, this mechanism does not occur in our studies because, as already mentioned, in the experiment on $\mathrm{KU}$ influence on the EtOH tolerance development, the KU and water combined administration did not affect the concentration of both ghrelin forms. Hence, it seems that the reason for the decrease in ghrelin concentrations after administration of KU, in the presence of alcohol, is the unknown mechanism of compounds interaction present in the P. lobata root extract.

The subsequent studies also examined the effect of isoflavonoids from KU, namely DAI and PUE, on ghrelin levels. Similarly to AC and NAL administration, ghrelin leveling effects were observed in PR animals that received these isoflavonoids. DAI administration normalized the concentrations of both ghrelin forms in relation to the concentrations observed for the control NP animals. However, DAI did not change the levels of this peptide in NP rats. In the case of PUE, the normalization of level was observed only for the total ghrelin, whereas the active ghrelin form increased both in PR and (not significantly) in NP rats in comparison to control values.

It should be emphasized that the observed changes in ghrelin concentrations, under the influence of alcohol and substances used in our study, are related to an unknown but rather specific alcohol effect. It is highly possible because no changes in the body mass of rats or total fluid intake were noticed throughout the entire experiment. Therefore, the alcohol-ghrelin interrelation is not simply linked to the impact on the hunger or appetite center, where there is a correlation between ghrelin level and the feeling of hunger [101]. Although the mechanism by which AC, NAL, and both isoflavonoids could affect ghrelin levels is unknown, it is strongly correlated with a clear reduction in alcohol consumption in PR rats.

\section{Materials and Methods}

\subsection{Substances and Drugs}

The following reagents, substances and drugs were used in our study: ethyl alcohol-95\% rectified spirit (Polmos, Bielsko-Biała, Poland); methylcellulose (MC) (Sigma-Chemical CO., Tokyo, Japan); water for injection $\left(\mathrm{H}_{2} \mathrm{O}\right)$ - “"Aqua pro iniectione" (Fresenius Kabi Polska Sp. z o.o., Kutno, Poland); acamprosate (AC)-333 mg film-coated tablets (Campral) (Merck Sante, Semoy, France); naltrexone (NAL)—substance (98\%) (Sigma-Aldrich, Poznań, Poland); Pueraria lobata (KU)-EtOH extract from the root of kudzu (KU)—extractum siccum (P.L. Thomas and Co., Inc., Morristown, NJ, USA); daidzin (DAI) (98\%)—Glycine mass. (L.) Merr. (Shaanxi Sciphar Biotechnology Co., Ltd., Nanjing, China); puerarin (PUE) (98\%)—Glycine mass. (L.) Merr. (Shaanxi Sciphar Biotechnology Co., Ltd., Nanjing, China).

\subsection{Determination of Isoflavones in KU}

Isoflavonoids from KU were analyzed according to the monograph for "Kudzu vine root" from European Pharmacopeia 8th and similarly to our previous research [90]. Briefly, reference substances (daidzin, daidzein) and acetic acid were obtained from Sigma-Aldrich (Millipore Sigma, Burlington, MA, USA). Standardized "Kudzu vine root" dry extract was obtained by EDQM. Ethanol and acetonitrile were purchased from J. T. Baker (J. T. Baker, Phillipsburg, NJ, USA).

Sample test: Approximately $0.6 \mathrm{~g}$ of dry extract was placed in a $250 \mathrm{~mL}$ roundbottomed flask and extracted with $50.0 \mathrm{~mL}$ of $30 \%$ ethanol under the reflux condenser for $30 \mathrm{~min}$. After cooling down, the sample was transferred to a $50 \mathrm{~mL}$ volumetric flask and filled up with $30 \%$ ethanol. Next, $1.0 \mathrm{~mL}$ of this solution was transferred to a $25 \mathrm{~mL}$ 
volumetric flask and filled up with $30 \%$ ethanol and filtered through the $0.45 \mu \mathrm{m}$ filters. Reference solutions: Approximately $30 \mathrm{mg}$ of standardized "Kudzu vine root" dry extract was placed in a $250 \mathrm{~mL}$ round-bottomed flask and extracted with $50.0 \mathrm{~mL}$ of $30 \%$ ethanol under the reflux condenser for $30 \mathrm{~min}$. After cooling down, the solution was filtered through the $0.45 \mu \mathrm{m}$ filters. Approximately $1 \mathrm{mg}$ of daidzein was placed in a $10 \mathrm{~mL}$ volumetric flask and filled up with $30 \%$ ethanol. Similarly, approximately $1 \mathrm{mg}$ of daidzin was placed in a $10 \mathrm{~mL}$ volumetric flask and filled up with $30 \%$ ethanol.

HPLC-DAD analysis: An identification of isoflavonoids was performed on Agilent 1100 (Agilent, Santa Clara, CA, USA). Compounds were identified on LiChrospher 100 RP18e, $150 \mathrm{~mm} \times 4 \mathrm{~mm} \times 5 \mu \mathrm{m}$ (Merck, Darmstadt, Germany). The mixture of two mobile phases eluted the compounds: $\mathrm{CH} 3 \mathrm{COOH}$ : water 0.1:99.9 $(v / v)$ (phase A) and acetonitrile (phase B) were used in the gradient separation procedure. The separation was performed in the following conditions: $0 \mathrm{~min}-10 \%$ phase $\mathrm{B}, 16.5 \mathrm{~min}-29 \%$ phase $\mathrm{B}$. The column temperature was $25^{\circ} \mathrm{C}$, the flow rate was $3.0 \mathrm{~mL} / \mathrm{min}$, the detection was at $\lambda=260 \mathrm{~nm}$, and the injection- $-10 \mu \mathrm{L}$. The peaks from the sample were identified by comparing the retention time and UV-VIS spectra with peaks from standardized "Kudzu vine root" dry extract (relative retention time described in the monograph). Relative retention with reference was as follows: to puerarin-about $2.1 \mathrm{~min}$; 3-hydroxypuerarin-about 0.7; 3-methoxypuerarin-about 1.09; 6-O $\mathrm{O}^{\prime \prime}$-D-xylosypuerarin-about 1.15; daidzin-about 1.4. The concentrations of all substances were expressed as puerarin.

\subsection{Animals and Experimental Protocols}

The study was performed on male Wistar rats. The animals were obtained from the laboratory animal facilities (Laboratory Animals Cultivation, Lipiec Zbigniew, Brwinów, Poland) and they were used in the part of our study on the effect of substances/drugs on alcohol intake behavior. In the experiment on the development of alcohol tolerance (part of study on the effect of $\mathrm{KU}$ on $\mathrm{EtOH}$ tolerance development) male alcohol Warsaw High-Preferring Wistar rats (WHP; 56-58 generation, from the Institute of Psychiatry and Neurology, Warsaw, Poland) with a high voluntary EtOH intake were used as in our previous study [47].

All animals were kept in separate plastic cages $(35(\mathrm{l}) \times 20(\mathrm{w}) \times 13(\mathrm{~h}) \mathrm{cm}$ with stainless steel covers) in a room with a temperature of $20 \pm 2{ }^{\circ} \mathrm{C}, 65-75 \%$ humidity, and reversed circadian cycle (7 p.m. to 7 a.m. light). The rats had free access to water (except for the induction period), standard laboratory diet (pellets, Labofeed B) (except for $12 \mathrm{~h}$ before decapitation), and in respective periods of the study-10\% (w/w) EtOH solution.

In order to select the alcohol-preferring animals (PR) as well as animals without such preference (non-preferring-NP) the procedure used before was applied $[47,74,102,103]$, with slight modifications. This procedure is outlined in a Scheme 1.

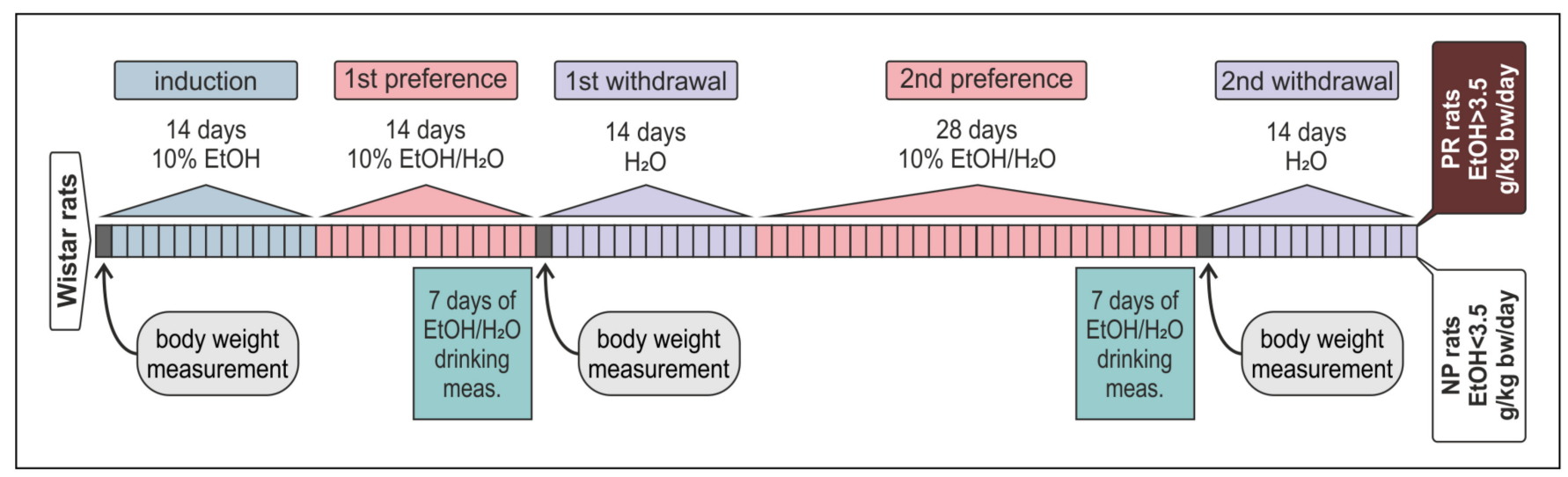

Scheme 1. Diagram of the Wistar rats' addiction process. 
Briefly, for the first 2 weeks, Wistar rats were forced to drink only EtOH solution (10\% $w / w)$. During the next 2 weeks, the animals were presented with a free-choice paradigm between tap water and $\mathrm{EtOH}$ (first preference period). Alcohol and water intake for every rat was recorded daily for the last 7 days of the preference period. The volumes of EtOH intake were converted to a value in $\mathrm{g} / \mathrm{kg} /$ day and expressed as a mean \pm SEM for the seven-day record. Similarly, the total fluid intake (the sum of water intakes and $\mathrm{EtOH}$ solution) was also defined as $\mathrm{g} / \mathrm{kg} /$ day for all the groups. The next step involved the two-week alcohol withdrawal period, and rats were only provided with tap water. On the first day of the withdrawal period (after the first preference period), the body weight of rats was recorded for recalculation of the amount of drinking EtOH or water $/ \mathrm{kg}$. For the following 4 weeks, animals had free access to water and $\mathrm{EtOH}$ solution (second preference period). Again, in the 4th week, another set of fluid intake measurements was conducted on a daily basis. The body weight of animals on the first day of the second withdrawal period (after the second preference period) was recorded. According to second set of fluid intake measurements, EtOH treated animals were divided into two groups: (1) rats with a mean intake of EtOH exceeding $50 \%$ of the total fluid, (>3.5 g/ kg/day), i.e., 'preferring' (PR) rats, and (2) rats in which alcohol solution constituted less than $50 \%$ of total fluid intake, i.e., 'non-preferring' (NP) rats.

\subsection{Measurements of the Animals' Body Weight}

The animals were weighed before each experiment. In the experiments with long-term alcohol consumption and administration of substances or drugs, the measurements of body weight were taken at the beginning of each subsequent cycle to correctly calculate the amount (dose) of $\mathrm{EtOH}$ and water consumed $/ \mathrm{kg}$ of body weight. In the further analysis, it was also considered whether the substances, drugs and alcohol affected the body weight of the animals.

\subsection{KU, DAI, PUE, AC, and NAL Administration}

This study involved five independent experiments according to the same model, carried out on PR and NP animals. After the procedure of obtaining the PR and NP animals, they were divided depending on the experiment into appropriate groups. Each group received a given substance or drug and the appropriate vehicle $(0.5 \%$ methylcellulose (MC) for KU, DAI, PUE, AC, or water for injection $\left(\mathrm{H}_{2} \mathrm{O}\right)$ for $\mathrm{NAL}$ ) once a day for 28 consecutive days (see Scheme 2).

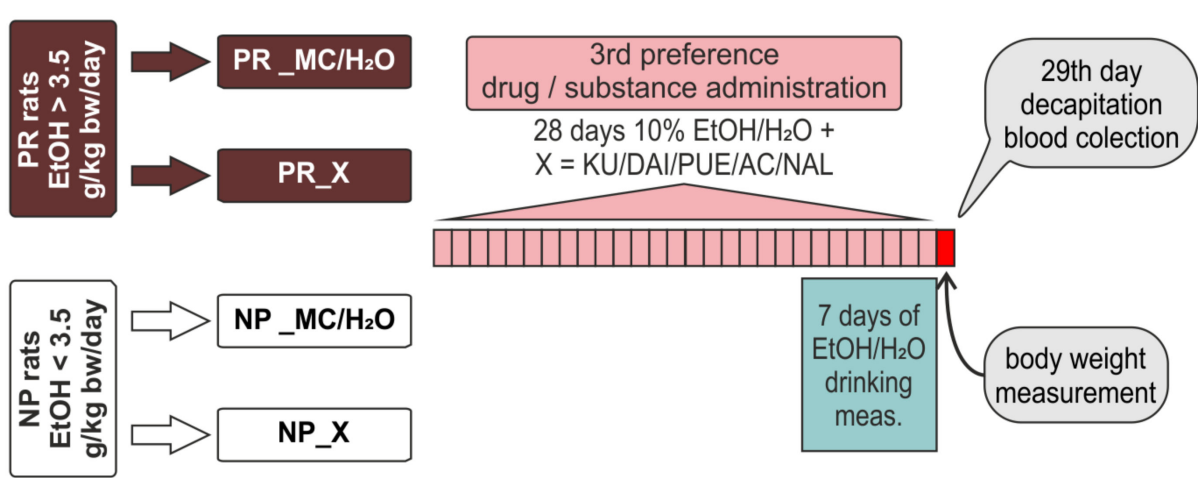

Scheme 2. Diagram of the division into test groups and the course of experiments.

The doses of individual substances, along with the information on the type of solvent for substances and the number of animals used in each group, are presented in Table 2. 
Table 2. Doses, concentrations and routes of administration for individual substances in a suitable solvent.

\begin{tabular}{|c|c|c|c|c|c|c|}
\hline Rats & Substance & Dose & Concentration & $\begin{array}{c}\text { Route of } \\
\text { Administration }\end{array}$ & Solvent & Treatment \\
\hline \multirow{5}{*}{$\frac{\vec{t}}{\stackrel{0}{0}}$} & $\mathrm{KU}$ & $500 \mathrm{mg} / \mathrm{kg}$ bw & $1000 \mathrm{mg} / 10 \mathrm{~mL}$ & p.o. & $0.5 \% \mathrm{MC}$ & \multirow{5}{*}{$\begin{array}{l}\text { once daily } \\
\text { for } 28 \text { days }\end{array}$} \\
\hline & DAI & $40 \mathrm{mg} / \mathrm{kg} \mathrm{bw}$ & $100 \mathrm{mg} / 10 \mathrm{~mL}$ & p.o. & $0.5 \% \mathrm{MC}$ & \\
\hline & PUE & $150 \mathrm{mg} / \mathrm{kg}$ bw & $100 \mathrm{mg} / 10 \mathrm{~mL}$ & p.o. & $0.5 \% \mathrm{MC}$ & \\
\hline & $\mathrm{AC}$ & $500 \mathrm{mg} / \mathrm{kg}$ bw & $1000 \mathrm{mg} / 10 \mathrm{~mL}$ & p.o. & $0.5 \% \mathrm{MC}$ & \\
\hline & NAL & $0.1 \mathrm{mg} / \mathrm{kg}$ bw & $1 \mathrm{mg} / 10 \mathrm{~mL}$ & i.p. & water for injection & \\
\hline WHP & KU & $500 \mathrm{mg} / \mathrm{kg}$ bw & $1000 \mathrm{mg} / 10 \mathrm{~mL}$ & p.o. & $0.5 \% \mathrm{MC}$ & $\begin{array}{l}\text { once daily } \\
\text { for } 9 \text { days }\end{array}$ \\
\hline
\end{tabular}

The volumes of EtOH intake were converted to a value in $\mathrm{g} / \mathrm{kg} /$ day and expressed as a mean \pm SEM for each group during the last week of drug/substance treatment. Similarly, the total fluid intake (the sum of intakes of water and EtOH solution) was also expressed as $\mathrm{g} / \mathrm{kg} /$ day for the groups during the last week of drug administration.

\subsection{KU Administration and the Development of EtOH Tolerance}

The next experiment was planned over KU influence on EtOH tolerance development, using animals with genetically conditioned preference for voluntary alcohol intake (WHP). The tolerance was established by a daily intraperitoneal administration of EtOH at a dose of $3 \mathrm{~g} / \mathrm{kg}$ for 9 consecutive days, according to the model proposed by Crabbe et al. [104] with some modifications [89-91]. This procedure is outlined in Scheme 3.

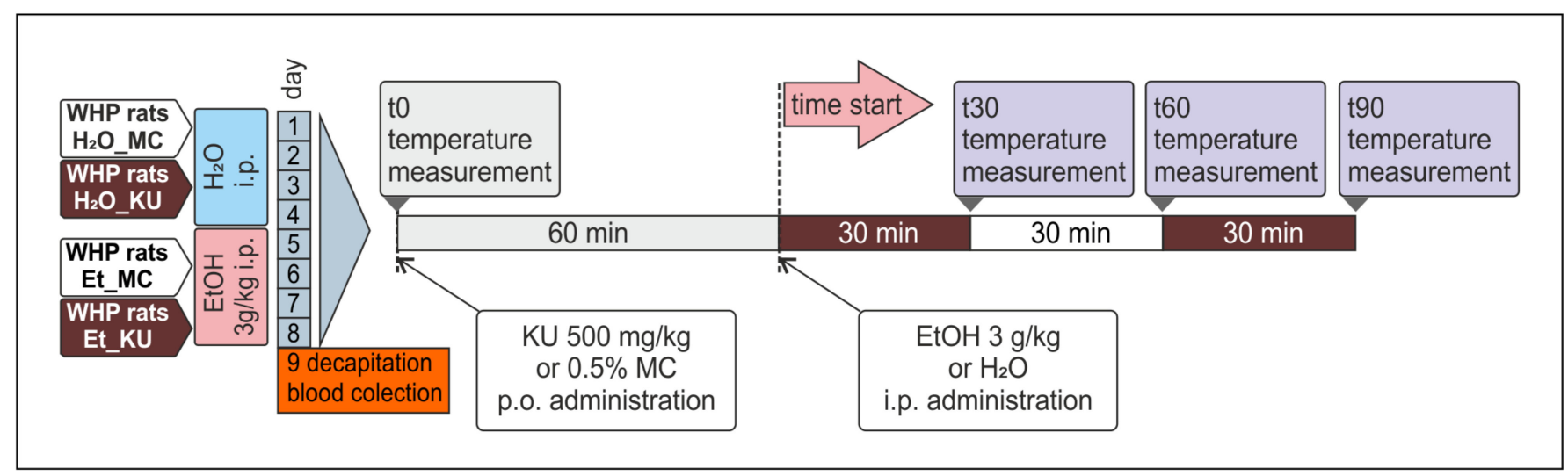

Scheme 3. KU administration and alcohol tolerance development during a 9-day protocol.

Briefly, the rats were weighed and randomly divided into four groups: two groups with $\mathrm{KU}(500 \mathrm{mg} / \mathrm{kg}$, p.o.) and two control groups which were intragastrically treated with $0.5 \%$ methylcellulose (MC) in complementary volumes. One hour after the KU administration, the rats were intraperitoneally injected with $30 \% \mathrm{EtOH}$ at a dose of $3 \mathrm{~g} / \mathrm{kg}$ or with water at complementary volume, respectively. Such a schedule was repeated for 9 consecutive days in order to develop alcohol tolerance in animals. On the first, third, fifth and eighth days, the animals' body temperatures were measured to evaluate the hypothermic action of EtOH: once before the treatment $(t=0)$ (at the beginning of the experiment) and at three time points after the alcohol injection (30,60, and 90 min after $\mathrm{EtOH})$. The measurements were performed using a calibrated rectal electronic thermometer (TTK-3011, Temed, Zabrze, Poland). The probe of the apparatus was inserted into rectum for $20 \mathrm{~s}$, which enabled establishing the temperature value on the scale. On the 9th day of the experiment, all animals were sacrificed by decapitation and peripheral blood was immediately collected for future analysis. 


\subsection{Serum Sampling and Protection for Downstream Analyzes}

The animals subjected to measurement of ghrelin levels did not receive any food in the last $12 \mathrm{~h}$ before sacrifice in order to avoid the influence of food on ghrelin levels. After decapitation, blood samples $(5 \mathrm{~mL})$ were immediately taken on $1 \mathrm{mM}$ ethylenediaminetetraacetic acid (EDTA, Sigma-Aldrich, Poznań, Poland) $(500 \mu \mathrm{L})$ to avoid clotting, and on $100 \mu \mathrm{L}$ of $1 \%$ p-hydroxymercuribenzoic acid (98\%, Sigma-Aldrich, St. Louis, MO, USA) to prevent protein degradation by proteases. Next, the blood was centrifuged for $15 \mathrm{~min}$ (4500 r.p.m.) at a temperature of $4{ }^{\circ} \mathrm{C}$. The acquired serum in the amount of $1.0 \mathrm{~mL}$ was secured by addition of $100 \mu \mathrm{L} 1 \mathrm{M} \mathrm{HCl}$ to stabilize the sample and left to freeze at $-80{ }^{\circ} \mathrm{C}$ for further measurements.

\subsection{Measuring the Total and Active Ghrelin Levels}

The measurement of total ghrelin concentration in the serum was determined using highly sensitive enzyme linked immunosorbent assay (ELISA) method and the commercially available kit (Phoenix Pharmaceuticals, Inc., Belmont, CA, USA) with 10 pg/mL detection limit.

The determination of active ghrelin (acylated) level in the serum was carried out by the ELISA method using the commercially available kit (SPI-Bio, Massy Cedex, France) with $1 \mathrm{pg} / \mathrm{mL}$ detection limit. All measurements were performed using the TECAN Sunrise ELISA plate reader (TECAN Austria Ges.m.b.H., Salzburg, Austria) and all stages of quantifications were carried out in accordance with the instructions attached in the form of a manufacturer's protocol.

\subsection{Statistical Analysis}

The obtained values of repetitions in the groups were averaged and presented as arithmetic means \pm SEM. Statistical calculations were performed using one-way analysis of variance (ANOVA) or ANOVA with replication and Fisher's least significant difference post hoc test using the Statistica 13 program. The $p$-values $<0.05$ were considered significant.

\section{Conclusions}

In conclusion, there was a proportional relationship between the anti-alcohol effect (reducing the alcohol-drinking reflex) of drugs (AC and NAL) or isoflavonoids (DAI and PUE) and the normalization in the levels of both ghrelin forms (active and total), which was still not observed for the effect of KU. Based on the above, it could be assumed that the peripheral concentration of both ghrelin forms may play an intriguing role as an indicator of alcohol-induced behavior, especially when controlling the effectiveness of currently used drugs. Nevertheless, this indicator should be treated with caution due to the fact that there are different alcohol intake vs. ghrelin level relationships while applying KU and its isoflavonoids. It is essential to stress that the action of $\mathrm{KU}$ on the ghrelin level is specific, and is not linked to its caloric value. Either way, the elucidation of KU-induced shift in ghrelin levels in the presence of EtOH requires further detailed study.

Author Contributions: Methodology, investigation, formal analysis and visualization, M.S.; conceptualization and design, P.Ł.M.; data analysis, interpretation of findings, preparation of the manuscript, M.S. and P.E.M.; supervision, R.K.; resources, J.B. and M.K.-D.; investigations, A.G. and E.K.; review and editing, K.C.-P. and H.W. All authors have read and agreed to the published version of the manuscript.

Funding: This study was funded by the Polish Ministry of Science and Higher Education, Grant No. NN 405358737.

Institutional Review Board Statement: The study was conducted at the Department of Pharmacology of the Poznań University of Medical Sciences, Poland, according to the guidelines of the Declaration of Helsinki, the Animal Experiment Reports of Experiences In Vivo (ARRIVE) guidelines and approved by the Local Ethical Committee for Animal Experiments (approval number: 03/2008). 
Informed Consent Statement: Not applicable.

Data Availability Statement: The data presented in this study are available upon request from the corresponding authors.

Acknowledgments: The authors would like to thank Wanda Dyr and Edyta Wyszogrodzka from the Institute of Psychiatry and Neurology, Warsaw, Poland for providing WHP animals for alcohol tolerance research and Radosław Kowalski, for his suitable technical assistance.

Conflicts of Interest: The authors declare that they have no competing interest. The funders had no role in the design of the study; in the collection, analysis, or interpretation of data; in the writing of the manuscript, or in the decision to publish the results.

\section{References}

1. Shield, K.D.; Parry, C.; Rehm, J. Chronic diseases and conditions related to alcohol use. Alcohol Res. 2013, 35, 155-173.

2. Ramalho, R. Alcohol consumption and alcohol-related problems during the COVID-19 pandemic: A narrative review. Australas. Psychiatry 2020, 28, 524-526. [CrossRef]

3. Institute of Medicine; National Research Council; Division of Behavioral and Social Sciences and Education; Board on Children, Youth, and Families; Committee on Developing a Strategy to Reduce and Prevent Underage Drinking. Reducing Underage Drinking: A Collective Responsibility; National Academies Press: Washington, DC, USA, 2004; ISBN 9780309089357.

4. Gilburt, H.; Drummond, C.; Sinclair, J. Navigating the Alcohol Treatment Pathway: A Qualitative Study from the Service Users' Perspective. Alcohol Alcohol. 2015, 50, 444-450. [CrossRef]

5. Klimas, J.; Fairgrieve, C.; Tobin, H.; Field, C.-A.; O'Gorman, C.S.; Glynn, L.G.; Keenan, E.; Saunders, J.; Bury, G.; Dunne, C.; et al. Psychosocial interventions to reduce alcohol consumption in concurrent problem alcohol and illicit drug users. Cochrane Database Syst. Rev. 2018, 12, CD009269. [CrossRef] [PubMed]

6. National Institute on Drug Abuse. Principles of Effective Treatment. Available online: https://www.drugabuse.gov/publications/ principles-drug-addiction-treatment-research-based-guide-third-edition/principles-effective-treatment (accessed on 22 September 2021).

7. O'Malley, S.S.; O'Connor, P.G. Medications for unhealthy alcohol use: Across the spectrum. Alcohol Res. Health 2011, 33, 300-312.

8. Witkiewitz, K.; Litten, R.Z.; Leggio, L. Advances in the science and treatment of alcohol use disorder. Sci. Adv. 2019, 5, eaax4043. [CrossRef] [PubMed]

9. Zhang, S.; Wang, J.; Zhao, H.; Luo, Y. Effects of three flavonoids from an ancient traditional Chinese medicine on geriatric diseases. Brain Circ. 2018, 4, 174-184. [PubMed]

10. Keung, W.M. Anti-dipsotropic isoflavones: The potential therapeutic agents for alcohol dependence. Med. Res. Rev. 2003, 23, 669-696. [CrossRef]

11. Overstreet, D.H.; Lee, D.Y.-W.; Chen, Y.T.; Rezvani, A.H. The Chinese herbal medicine NPI-028 suppresses alcohol intake in alcohol-preferring rats and monkeys without inducing taste aversion. Focus Altern. Complement. Ther. 2010, 2, 194. [CrossRef]

12. Mikolajczak, P. Postep w badaniach nad wykorzystaniem surowcow roslinnych w terapii uzaleznienia alkoholowego. Herba Pol. 2006, 4, 133-145.

13. Ulbricht, C.; Costa, D.; Dam, C.; D’Auria, D.; Giese, N.; Isaac, R.; LeBlanc, Y.; Rusie, E.; Weissner, W.; Windsor, R.C. An evidencebased systematic review of kudzu (Pueraria lobata) by the Natural Standard Research Collaboration. J. Diet. Suppl. 2015, 12, 36-104. [CrossRef]

14. Keung, W.M.; Vallee, B.L. Daidzin and daidzein suppress free-choice ethanol intake by Syrian golden hamsters. Proc. Natl. Acad. Sci. USA 1993, 90, 10008-10012. [CrossRef] [PubMed]

15. Lin, R.C.; Guthrie, S.; Xie, C.-Y.; Mai, K.; Lee, D.Y.; Lumeng, L.; Li, T.-K. Isoflavonoid Compounds Extracted from Pueraria lobata Suppress Alcohol Preference in a Pharmacogenetic Rat Model of Alcoholism. Alcohol. Clin. Exp. Res. 1996, 20, 659-663. [CrossRef]

16. Penetar, D.M.; Toto, L.H.; Farmer, S.L.; Lee, D.Y.-W.; Ma, Z.; Liu, Y.; Lukas, S.E. The isoflavone puerarin reduces alcohol intake in heavy drinkers: A pilot study. Drug Alcohol Depend. 2012, 126, 251-256. [CrossRef] [PubMed]

17. Lukas, S.E.; Penetar, D.; Berko, J.; Vicens, L.; Palmer, C.; Mallya, G.; Macklin, E.A.; Lee, D.Y.-W. An Extract of the Chinese Herbal Root Kudzu Reduces Alcohol Drinking by Heavy Drinkers in a Naturalistic Setting. Alcohol. Clin. Exp. Res. 2005, 29, 756-762. [CrossRef] [PubMed]

18. Lukas, S.E.; Penetar, D.; Su, Z.; Geaghan, T.; Maywalt, M.; Tracy, M.; Rodolico, J.; Palmer, C.; Ma, Z.; Lee, D.Y.-W. A standardized kudzu extract (NPI-031) reduces alcohol consumption in nontreatment-seeking male heavy drinkers. Psychopharmacology 2013, 226, 65-73. [CrossRef] [PubMed]

19. Bracken, B.K.; Penetar, D.M.; Maclean, R.R.; Lukas, S.E. Kudzu root extract does not perturb the sleep/wake cycle of moderate drinkers. J. Altern. Complement. Med. 2011, 17, 961-966. [CrossRef] [PubMed]

20. Penetar, D.M.; Toto, L.H.; Lee, D.Y.-W.; Lukas, S.E. A single dose of kudzu extract reduces alcohol consumption in a binge drinking paradigm. Drug Alcohol Depend. 2015, 153, 194-200. [CrossRef] [PubMed]

21. Oh, J.H.; Baek, S.-E.; Lee, W.-Y.; Baek, J.Y.; Trinh, T.A.; Park, D.H.; Lee, H.L.; Kang, K.S.; Kim, C.-E.; Yoo, J.-E. Investigating the Systems-Level Effect of Pueraria lobata for Menopause-Related Metabolic Diseases Using an Ovariectomized Rat Model and Network Pharmacological Analysis. Biomolecules 2019, 9, 747. [CrossRef] 
22. Jung, H.W.; Kang, A.N.; Kang, S.Y.; Park, Y.-K.; Song, M.Y. The Root Extract of Pueraria lobata and Its Main Compound, Puerarin, Prevent Obesity by Increasing the Energy Metabolism in Skeletal Muscle. Nutrients 2017, 9, 33. [CrossRef]

23. Yang, M.; Hu, Z.; Yue, R. Effect of pueraria, scutellaria, and coptis decoction for type 2 diabetes: A systematic review and meta-analysis protocol. Medicine 2020, 99, e19770. [CrossRef]

24. Luo, D.; Dong, X.; Huang, J.; Huang, C.; Fang, G.; Huang, Y. Pueraria lobata root polysaccharide alleviates glucose and lipid metabolic dysfunction in diabetic db/db mice. Pharm. Biol. 2021, 59, 382-390. [CrossRef]

25. Lertpatipanpong, P.; Janpaijit, S.; Park, E.-Y.; Kim, C.-T.; Baek, S.J. Potential Anti-Diabetic Activity of Pueraria lobata Flower (Flos Puerariae) Extracts. Molecules 2020, 25, 3970. [CrossRef] [PubMed]

26. Jin, S.E.; Son, Y.K.; Min, B.-S.; Jung, H.A.; Choi, J.S. Anti-inflammatory and antioxidant activities of constituents isolated from Pueraria lobata roots. Arch. Pharm. Res. 2012, 35, 823-837. [CrossRef] [PubMed]

27. Eom, S.H.; Jin, S.-J.; Jeong, H.-Y.; Song, Y.; Lim, Y.J.; Kim, J.-I.; Lee, Y.-H.; Kang, H. Kudzu Leaf Extract Suppresses the Production of Inducible Nitric Oxide Synthase, Cyclooxygenase-2, Tumor Necrosis Factor-Alpha, and Interleukin-6 via Inhibition of JNK, TBK1 and STAT1 in Inflammatory Macrophages. Int. J. Mol. Sci. 2018, 19, 1536. [CrossRef] [PubMed]

28. Wang, S.; Zhang, S.; Wang, S.; Gao, P.; Dai, L. A comprehensive review on Pueraria: Insights on its chemistry and medicinal value. Biomed. Pharmacother. 2020, 131, 110734. [CrossRef] [PubMed]

29. Larsson, A.; Engel, J.A. Neurochemical and behavioral studies on ethanol and nicotine interactions. Neurosci. Biobehav. Rev. 2004, 27, 713-720. [CrossRef]

30. Engel, J.A.; Jerlhag, E. Role of appetite-regulating peptides in the pathophysiology of addiction: Implications for pharmacotherapy. CNS Drugs 2014, 28, 875-886. [CrossRef]

31. Söderpalm, B.; Ericson, M. Neurocircuitry involved in the development of alcohol addiction: The dopamine system and its access points. Curr. Top. Behav. Neurosci. 2013, 13, 127-161.

32. Kojima, M.; Hosoda, H.; Date, Y.; Nakazato, M.; Matsuo, H.; Kangawa, K. Ghrelin is a growth-hormone-releasing acylated peptide from stomach. Nature 1999, 402, 656-660. [CrossRef]

33. Jerlhag, E.; Janson, A.C.; Waters, S.; Engel, J.A. Concomitant release of ventral tegmental acetylcholine and accumbal dopamine by ghrelin in rats. PLoS ONE 2012, 7, e49557.

34. Overstreet, D.H.; Kralic, J.E.; Leslie Morrow, A.; Ma, Z.Z.; Zhang, Y.W.; Lee, D.Y.W. NPI-031G (puerarin) reduces anxiogenic effects of alcohol withdrawal or benzodiazepine inverse or 5-HT2C agonists. Pharmacol. Biochem. Behav. 2003, 75, 619-625. [CrossRef]

35. Bogdanov, V.B.; Bogdanova, O.V.; Dexpert, S.; Delgado, I.; Beyer, H.; Aubert, A.; Dilharreguy, B.; Beau, C.; Forestier, D.; Ledaguenel, P.; et al. Reward-related brain activity and behavior are associated with peripheral ghrelin levels in obesity. Psychoneuroendocrinology 2020, 112, 104520. [CrossRef]

36. Jerlhag, E. Gut-brain axis and addictive disorders: A review with focus on alcohol and drugs of abuse. Pharmacol. Ther. 2019, 196, 1-14. [CrossRef]

37. Banks, W.A.; Tschöp, M.; Robinson, S.M.; Heiman, M.L. Extent and direction of ghrelin transport across the blood-brain barrier is determined by its unique primary structure. J. Pharmacol. Exp. Ther. 2002, 302, 822-827. [CrossRef] [PubMed]

38. Abizaid, A.; Liu, Z.-W.; Andrews, Z.B.; Shanabrough, M.; Borok, E.; Elsworth, J.D.; Roth, R.H.; Sleeman, M.W.; Picciotto, M.R.; Tschöp, M.H.; et al. Ghrelin modulates the activity and synaptic input organization of midbrain dopamine neurons while promoting appetite. J. Clin. Investig. 2006, 116, 3229-3239. [CrossRef] [PubMed]

39. Skibicka, K.P. The central GLP-1: Implications for food and drug reward. Front. Neurosci. 2013, 7, 181. [CrossRef] [PubMed]

40. Suchankova, P.; Jerlhag, E.; Jayaram-Lindström, N.; Nilsson, S.; Toren, K.; Rosengren, A.; Engel, J.A.; Franck, J. Genetic variation of the ghrelin signalling system in individuals with amphetamine dependence. PLoS ONE 2013, 8, e61242.

41. Kern, A.; Albarran-Zeckler, R.; Walsh, H.E.; Smith, R.G. Apo-ghrelin receptor forms heteromers with DRD2 in hypothalamic neurons and is essential for anorexigenic effects of DRD2 agonism. Neuron 2012, 73, 317-332. [CrossRef]

42. Edvardsson, C.E.; Vestlund, J.; Jerlhag, E. A ghrelin receptor antagonist reduces the ability of ghrelin, alcohol or amphetamine to induce a dopamine release in the ventral tegmental area and in nucleus accumbens shell in rats. Eur. J. Pharmacol. 2021, 899, 174039. [CrossRef] [PubMed]

43. Landgren, S.; Simms, J.A.; Hyytiä, P.; Engel, J.A.; Bartlett, S.E.; Jerlhag, E. Ghrelin receptor (GHS-R1A) antagonism suppresses both operant alcohol self-administration and high alcohol consumption in rats. Addict. Biol. 2012, 17, 86-94. [CrossRef]

44. Jerlhag, E.; Egecioglu, E.; Dickson, S.L.; Engel, J.A. Glutamatergic regulation of ghrelin-induced activation of the mesolimbic dopamine system. Addict. Biol. 2011, 16, 82-91. [CrossRef] [PubMed]

45. Bahi, A.; Tolle, V.; Fehrentz, J.-A.; Brunel, L.; Martinez, J.; Tomasetto, C.-L.; Karam, S.M. Ghrelin knockout mice show decreased voluntary alcohol consumption and reduced ethanol-induced conditioned place preference. Peptides 2013, 43, 48-55. [CrossRef] [PubMed]

46. Mary, S.; Fehrentz, J.-A.; Damian, M.; Gaibelet, G.; Orcel, H.; Verdié, P.; Mouillac, B.; Martinez, J.; Marie, J.; Banères, J.-L. Heterodimerization with Its Splice Variant Blocks the Ghrelin Receptor 1a in a Non-signaling Conformation. J. Biol. Chem. 2013, 288, 24656-24665. [CrossRef]

47. Szulc, M.; Mikolajczak, P.L.; Geppert, B.; Wachowiak, R.; Dyr, W.; Bobkiewicz-Kozlowska, T. Ethanol affects acylated and total ghrelin levels in peripheral blood of alcohol-dependent rats. Addict. Biol. 2013, 18, 689-701. [CrossRef]

48. Healey, K.L.; Landin, J.D.; Dubester, K.; Kibble, S.; Marquardt, K.; Brutman, J.N.; Davis, J.F.; Swartzwelder, H.S.; Chandler, L.J Effects of ethanol on plasma ghrelin levels in the rat during early and late adolescence. Alcohol 2020, 85, 111-118. [CrossRef] 
49. Orellana, E.R.; Piscura, M.K.; Horvath, N.; Hajnal, A. Differential Response in Ethanol Behaviors of Female Rats Given Various Weight Loss Surgeries. Alcohol Alcohol. 2021, 56, 599-604. [CrossRef]

50. Kraus, T.; Schanze, A.; Gröschl, M.; Bayerlein, K.; Hillemacher, T.; Reulbach, U.; Kornhuber, J.; Bleich, S. Ghrelin levels are increased in alcoholism. Alcohol. Clin. Exp. Res. 2005, 29, 2154-2157. [CrossRef] [PubMed]

51. Addolorato, G.; Capristo, E.; Leggio, L.; Ferrulli, A.; Abenavoli, L.; Malandrino, N.; Farnetti, S.; Domenicali, M.; D’Angelo, C.; Vonghia, L.; et al. Relationship Between Ghrelin Levels, Alcohol Craving, and Nutritional Status in Current Alcoholic Patients. Alcohol. Clin. Exp. Res. 2006, 30, 1933-1937. [CrossRef] [PubMed]

52. Badaoui, A.; De Saeger, C.; Duchemin, J.; Gihousse, D.; de Timary, P.; Stärkel, P. Alcohol dependence is associated with reduced plasma and fundic ghrelin levels. Eur. J. Clin. Investig. 2008, 38, 397-403. [CrossRef]

53. Calissendorff, J.; Gustafsson, T.; Holst, J.J.; Brismar, K.; Röjdmark, S. Alcohol intake and its effect on some appetite-regulating hormones in man: Influence of gastroprotection with sucralfate. Endocr. Res. 2012, 37, 154-162. [CrossRef]

54. Koob, G.F. Animal models of craving for ethanol. Addiction 2000, 95, 73-81. [CrossRef]

55. Samson, H.H. The microstructure of ethanol drinking: Genetic and behavioral factors in the control of drinking patterns. Addiction 2000, 95, 61-72. [CrossRef] [PubMed]

56. Spanagel, R.; Kiefer, F. Drugs for relapse prevention of alcoholism: Ten years of progress. Trends Pharmacol. Sci. 2008, 29, 109-115. [CrossRef] [PubMed]

57. Heyser, C.J.; Schulteis, G.; Koob, G.F. Increased Ethanol Self-Administration after a Period of Imposed Ethanol Deprivation in Rats Trained in a Limited Access Paradigm. Alcohol Clin. Exp. Res. 1997, 21, 784-791. [CrossRef] [PubMed]

58. Spanagel, R. Alcohol addiction research: From animal models to clinics. Best Pract. Res. Clin. Gastroenterol. 2003, 17, 507-518. [CrossRef]

59. Mikolajczak, P.; Wiktorowicz, K.; Okulicz-Kozaryn, I.; Kostrzewa, A.; Kaminska, E. Analysis of the distribution of peripheral blood lymphocyte subsets associated with chronic ethanol treatment in rats with a disturbed circadian cycle. Drug Alcohol Depend 2000, 60, 303-309. [CrossRef]

60. Mikolajczak, P.; Okulicz-Kozaryn, I.; Nowaczyk, M.; Kaminska, E. Ethanol facilitation of short-term memory in adult rats with a disturbed circadian cycle. Alcohol Alcohol. 2001, 36, 292-297. [CrossRef]

61. McGregor, I.S.; Gallate, J.E. Rats on the grog: Novel pharmacotherapies for alcohol craving. Addict. Behav. 2004, 29, 1341-1357. [CrossRef]

62. Piorunska-Mikolajczak, A.; Piorunska-Stolzmann, M.; Mikolajczak, P.; Okulicz-Kozaryn, I.; Kaminska, E. Acamprosate involvement in triacylglycerol hydrolysis and transacylation with cholesterol in chronically ethanol-drinking rats. J. Basic Clin. Physiol. Pharmacol. 2004, 15, 153-173. [CrossRef]

63. Whitworth, A.B.; Fischer, F.; Lesch, O.M.; Nimmerrichter, A.; Oberbauer, H.; Platz, T.; Potgieter, A.; Walter, H.; Fleischhacker, W.W. Comparison of acamprosate and placebo in long-term treatment of alcohol dependence. Lancet 1996, 347, 1438-1442. [CrossRef]

64. Mason, B.J. Acamprosate and naltrexone treatment for alcohol dependence: An evidence-based risk-benefits assessment. Eur. Neuropsychopharmacol. 2003, 13, 469-475. [CrossRef]

65. Mason, B.J.; Goodman, A.M.; Chabac, S.; Lehert, P. Effect of oral acamprosate on abstinence in patients with alcohol dependence in a double-blind, placebo-controlled trial: The role of patient motivation. J. Psychiatr. Res. 2006, 40, 383-393. [CrossRef] [PubMed]

66. Mann, K.; Kiefer, F.; Smolka, M.; Gann, H.; Wellek, S.; Heinz, A.; PREDICT Study Research Team. Searching for responders to acamprosate and naltrexone in alcoholism treatment: Rationale and design of the PREDICT study. Alcohol. Clin. Exp. Res. 2009, 33, 674-683. [CrossRef] [PubMed]

67. Diehl, A.; Ulmer, L.; Mutschler, J.; Herre, H.; Krumm, B.; Croissant, B.; Mann, K.; Kiefer, F. Why is disulfiram superior to acamprosate in the routine clinical setting? A retrospective long-term study in 353 alcohol-dependent patients. Alcohol Alcohol. 2010, 45, 271-277. [CrossRef]

68. Kalk, N.J.; Lingford-Hughes, A.R. The clinical pharmacology of acamprosate. Br. J. Clin. Pharmacol. 2014, 77, 315-323. [CrossRef]

69. Mason, B.J. Alcohol Use Disorder: The Role of Medication in Recovery. Alc. Res. Curr. Rev. 2021, 41. [CrossRef] [PubMed]

70. Koltunowska, D.; Gibula-Bruzda, E.; Kotlinska, J.H. The influence of ionotropic and metabotropic glutamate receptor ligands on anxiety-like effect of amphetamine withdrawal in rats. Prog. Neuropsychopharmacol. Biol. Psychiatry 2013, 45, 242-249. [CrossRef]

71. Hu, W.; Morris, B.; Carrasco, A.; Kroener, S. Effects of acamprosate on attentional set-shifting and cellular function in the prefrontal cortex of chronic alcohol-exposed mice. Alcohol. Clin. Exp. Res. 2015, 39, 953-961. [CrossRef] [PubMed]

72. Szulc, M.; Mikołajczak, P.; Okulicz-Kozaryn, I.; Kamińska, E.; Dyr, W.; Kostowski, W. Acamprosate effect on short-term memory in chronically EtOH treated rats. Pol. J. Pharmacol. 2002, 54, 539-540.

73. Gewiss, M.; Heidbreder, C.; Opsomer, L.; Durbin, P.; De Witte, P. Acamprosate and diazepam differentially modulate alcoholinduced behavioural and cortical alterations in rats following chronic inhalation of ethanol vapour. Alcohol Alcohol. 1991, 26, 129-137. [CrossRef] [PubMed]

74. Okulicz-Kozaryn, I.; Mikolajczak, P.; Kaminska, E.; Kaminska, I.; Szulc, M.; Bobkiewicz-Kozlowska, T. Effect of naltrexone administration on short-term memory in chronically ethanol-treated outbred rats. Alcohol Alcohol. 2004, 39, 14-19. [CrossRef]

75. Williams, K.L.; Woods, J.H. Naltrexone reduces ethanol- and/or water-reinforced responding in rhesus monkeys: Effect depends upon ethanol concentration. Alcohol. Clin. Exp. Res. 1999, 23, 1462-1467. [CrossRef] [PubMed] 
76. Heinälä, P.; Alho, H.; Kiianmaa, K.; Lönnqvist, J.; Kuoppasalmi, K.; Sinclair, J.D. Targeted use of naltrexone without prior detoxification in the treatment of alcohol dependence: A factorial double-blind, placebo-controlled trial. J. Clin. Psychopharmacol. 2001, 21, 287-292. [CrossRef] [PubMed]

77. Sinclair, J.D. Evidence about the use of naltrexone and for different ways of using it in the treatment of alcoholism. Alcohol Alcohol. 2001, 36, 2-10. [CrossRef] [PubMed]

78. Benlhabib, E.; Baker, J.I.; Keyler, D.E.; Singh, A.K. Kudzu root extract suppresses voluntary alcohol intake and alcohol withdrawal symptoms in P rats receiving free access to water and alcohol. J. Med. Food 2004, 7, 168-179. [CrossRef]

79. Benlhabib, E.; Baker, J.I.; Keyler, D.E.; Singh, A.K. Effects of Purified Puerarin on Voluntary Alcohol Intake and Alcohol Withdrawal Symptoms in P Rats Receiving Free Access to Water and Alcohol. J. Med. Food 2004, 7, 180-186. [CrossRef]

80. Keung, W.M.; Vallee, B.L. Kudzu root: An ancient Chinese source of modern antidipsotropic agents. Phytochemistry 1998, 47, 499-506. [CrossRef]

81. Overstreet, D.H.; Lee, Y.W.; Rezvani, A.H.; Pei, Y.H.; Criswell, H.E.; Janowsky, D.S. Suppression of alcohol intake after administration of the Chinese herbal medicine, NPI-028, and its derivatives. Alcohol. Clin. Exp. Res. 1996, 20, 221-227. [CrossRef]

82. Keung, W.M.; Lazo, O.; Kunze, L.; Vallee, B.L. Daidzin suppresses ethanol consumption by Syrian golden hamsters without blocking acetaldehyde metabolism. Proc. Natl. Acad. Sci. USA 1995, 92, 8990-8993. [CrossRef]

83. Xiao, B.; Sun, Z.; Cao, F.; Wang, L.; Liao, Y.; Liu, X.; Pan, R.; Chang, Q. Brain Pharmacokinetics and the Pharmacological Effects on Striatal Neurotransmitter Levels of Pueraria lobata Isoflavonoids in Rat. Front. Pharmacol. 2017, 8. [CrossRef]

84. Zhang, Z.; Li, S.; Jiang, J.; Yu, P.; Liang, J.; Wang, Y. Preventive effects of Flos Perariae (Gehua) water extract and its active ingredient puerarin in rodent alcoholism models. Chin. Med. 2010, 5, 36. [CrossRef] [PubMed]

85. Keung, W.M.; Lazo, O.; Kunze, L.; Vallee, B.L. Potentiation of the bioavailability of daidzin by an extract of Radix puerariae Proc. Natl. Acad. Sci. USA 1996, 93, 4284-4288. [CrossRef]

86. Heyman, G.M.; Keung, W.M.; Vallee, B.L. Daidzin decreases ethanol consumption in rats. Alcohol. Clin. Exp. Res. 1996, 20, 1083-1087. [CrossRef]

87. Matkowski, A.; Woźniak, D.; Oszmiański, J.; Lamer-Zarawska, E. Flavonoids of Pueraria lobata: Chromatographic analysis of leaves and roots of cultivated plants. Pharmazie 2003, 58, 682-683. [PubMed]

88. Zhang, G.; Ji, J.; Sun, M.; Ji, Y.; Ji, H. Comparative Pharmacokinetic Profiles of Puerarin in Rat Plasma by UHPLC-MS/MS after Oral Administration of Pueraria lobata Extract and Pure Puerarin. J. Anal. Methods Chem. 2020, 2020, 4258156. [CrossRef]

89. Szulc, M.; Mularczyk, P.; Kujawski, R.; Gryszczyńska, A.; Kamińska, E.; Geppert, B.; Baraniak, J.; Kania-Dobrowolska, M.; Ożarowski, M.; Krajewska-Patan, A.; et al. Influence of salidroside, a neuroactive compound of Rhodiola rosea L., on alcohol tolerance development in rats. Herba Pol. 2018, 64, 22-34. [CrossRef]

90. Szulc, M.; Mularczyk, P.; Grzadzielski, P.; Zakowicz, P.; Kujawski, R.; Gryszczynska, A.; Buchwald, W.; Tezyk, A.; Krajewska-Patan, A.; Kaminska, E.; et al. Influence of extracts from Rhodiola rosea and Rhodiola kirilowii on the development of alcohol tolerance in rats. Herba Pol. 2018, 64, 34-43. [CrossRef]

91. Okulicz-Kozaryn, I.; Mikolajczak, P.; Kaminska, E. Tolerance to hypothermia and hypnotic action of ethanol in 3 and 14 months old rats. Pharmacol. Res. 1992, 25, 63-64. [CrossRef]

92. Soyka, M.; Kranzler, H.R.; Berglund, M.; Gorelick, D.; Hesselbrock, V.; Johnson, B.A.; Möller, H.-J. WFSBP Task Force on Treatment Guidelines for Substance Use Disorders World Federation of Societies of Biological Psychiatry (WFSBP) Guidelines for Biological Treatment of Substance Use and Related Disorders, Part 1: Alcoholism. World J. Biol. Psychiatry 2008, 9, 6-23. [CrossRef] [PubMed]

93. Schuckit, M.A. Alcohol-use disorders. Lancet 2009, 373, 492-501. [CrossRef]

94. Landgren, S.; Engel, J.A.; Hyytiä, P.; Zetterberg, H.; Blennow, K.; Jerlhag, E. Expression of the gene encoding the ghrelin receptor in rats selected for differential alcohol preference. Behav. Brain Res. 2011, 221, 182-188. [CrossRef] [PubMed]

95. Deschaine, S.L.; Farokhnia, M.; Gregory-Flores, A.; Zallar, L.J.; You, Z.-B.; Sun, H.; Harvey, D.M.; Marchette, R.C.N.; Tunstall, B.J.; Mani, B.K.; et al. A closer look at alcohol-induced changes in the ghrelin system: Novel insights from preclinical and clinical data. Addict. Biol. 2021, e13033. [CrossRef] [PubMed]

96. Farokhnia, M.; Grodin, E.N.; Lee, M.R.; Oot, E.N.; Blackburn, A.N.; Stangl, B.L.; Schwandt, M.L.; Farinelli, L.A.; Momenan, R.; Ramchandani, V.A.; et al. Exogenous ghrelin administration increases alcohol self-administration and modulates brain functional activity in heavy-drinking alcohol-dependent individuals. Mol. Psychiatry 2018, 23, 2029-2038. [CrossRef] [PubMed]

97. Hicks, M.P.; Olive, M. Whole genome transcriptional profiling of the mouse frontal cortex following repeated acamprosate administration. In Proceedings of the 2nd WSEAS International Conference on Biomedical Electronics and Biomedical Informatics, Stevens Point, WI, USA, 20-22 August 2009; Volume 1, pp. 180-183.

98. Zigman, J.M.; Elmquist, J.K. Minireview: From anorexia to obesity-The yin and yang of body weight control. Endocrinology 2003, 144, 3749-3756. [CrossRef]

99. Chen, S.-R.; Chen, H.; Zhou, J.-J.; Pradhan, G.; Sun, Y.; Pan, H.-L.; Li, D.-P. Ghrelin receptors mediate ghrelin-induced excitation of agouti-related protein/neuropeptide $Y$ but not pro-opiomelanocortin neurons. J. Neurochem. 2017, 142, 512-520. [CrossRef]

100. Gomez, G.; Englander, E.W.; Greeley, G.H., Jr. Nutrient inhibition of ghrelin secretion in the fasted rat. Regul. Pept. 2004, 117, 33-36. [CrossRef]

101. Pradhan, G.; Samson, S.L.; Sun, Y. Ghrelin: Much more than a hunger hormone. Curr. Opin. Clin. Nutr. Metab. Care 2013, 16, 619-624. [CrossRef] 
102. Mikolajczak, P.; Okulicz-Kozaryn, I.; Szczawinska, K.; Kaminska, E.; Kus, K. Zolpidem involvement on memory and hypnotic effect of ethanol in chronically ethanol-treated rats. Alcohol Alcohol. 1999, 34, 511-519. [CrossRef] [PubMed]

103. Daoust, M.; Lhuintre, J.P.; Moore, N.; Saligaut, C.; Flipo, J.L.; Boismare, F. Is initial sensitivity to ethanol correlated with alcohol preference in alcohol-drinking and non-drinking rats? Alcohol Alcohol. 1987, 22, 409-414.

104. Crabbe, J.C.; Janowsky, J.S.; Young, E.R.; Kosobud, A.; Stack, J.; Rigter, H. Tolerance to ethanol hypothermia in inbred mice: Genotypic correlations with behavioral responses. Alcohol. Clin. Exp. Res. 1982, 6, 446-458. [CrossRef] [PubMed] 